American Journal of Environmental Sciences 8 (2): 79-94, 2012

ISSN 1553-345X

(C) 2012 Science Publications

\title{
Permeability, Strength and Filtration Performance for Uncoated and Titania-Coated Clay Wastewater Filters
}

\author{
Masturi, Silvia, Mahardika Prasetya Aji, \\ Euis Sustini, Khairurrijal and Mikrajuddin Abdullah \\ Department of Physic, Faculty of Mathematics and Natural Science, \\ Bandung Institute of Technology, Jl Ganeca 10 Bandung 40132, Indonesia
}

\begin{abstract}
Problem statement: Wastewater problems continue to be a relevant issue, particularly in urban areas. One promising low-cost material for manufacturing porous ceramics as water filter is clay. Clays can be blended with other materials such as polymers to obtain functional ceramic materials. Approach: Ceramic wastewater filters were fabricated from clay using both sol-gel and simple mixing methods followed by hot-pressing and calcination. Polyethylene Glycol (PEG) was used as a poreforming agent. Results: Varying the clay:PEG ratio modified the membrane permeability between $1.65 \times 10^{-16} \mathrm{~m}^{2}$ and $3.16 \times 10^{-15} \mathrm{~m}^{2}$ for the sol-gel membranes and between $1.38 \times 10^{-16}$ and $8.72 \times 10^{-13}$ $\mathrm{m}^{2}$ for membranes prepared by simple mixing. The strength ranged from $0.28 \mathrm{MPa}-1.71 \mathrm{MPa}$ for the sol-gel membranes and from 0.05-0.90 MPa for samples prepared by simple mixing. The filtration performance was tested using aqueous solutions of Methylene Blue (MB). The concentrations of MB remaining in the solution varied from $0.98-1.44 \%$ for sol-gel filters and from $1.50-38.05 \%$ for filters prepared by simple mixing. Conclusion: We succeeded in making ceramic as filter from clay. The porous ceramic can be used to reducing concentration of pollutant simulated. The model introduced has succeeded to explain the experimental observations with percolation approximation.
\end{abstract}

Key words: Polyethylene glycol, Methylene Blue (MB), Polyethylene Glycol (PEG), wastewater filter, permeability, strength, filtration performance, Effective Medium Approximation (EMA)

\section{INTRODUCTION}

Research in membrane technology is rapidly advancing due to the emerging utility of membranes in separations involving solid, liquid and gaseous materials (Palacio et al., 2009), particularly in environmental applications such as water purification. Since they are made from inorganic materials, ceramic membranes are potentially more useful for many more applications than polymer membranes due to properties such as high temperature resistance (Biesheuvel, 1999), chemical compatibility and durability in long-term use. In addition, if the pores become clogged during operation, the filters may be calcined at high temperature to remove organic contaminants. One promising low-cost material for manufacturing porous ceramics is clay, a mineral composed of hydrated aluminum silicates and other metal oxides such as $\mathrm{Fe}_{2} \mathrm{O}_{3}, \mathrm{MgO}$ and $\mathrm{K}_{2} \mathrm{O}$. Clays may be blended with other materials such as polymers and metals (Kuzugudenli, 2004) to obtain functional ceramic materials. Filters produced from modified clays can possess a high surface area (Hwang et al., 2006), be durable and reusable and exhibit thermal stability, chemical inertness and excellent mechanical strength (Velmurugan and Mohan, 2009; Alam et al., 2010; Selvaganapathi et al., 2010). One property that is typically improved in porous ceramics is permeability, or the ability of fluids to move in the pores of the material (Chilingarian, 1995). The permeability of unmodified clay is low because the intergranular spaces are very small. The pores may be enlarged by adding a polymer (Putyra et al., 2008) such as Polyethylene Glycol (PEG) that will decompose at the high temperatures experienced during the firing process. There has been a great deal of effort directed toward optimizing the permeability of porous ceramics formed from materials such as alumina (Biesheuvel, 1999) and Tunisian clay (Hamdi and Srasra, 2008). However, the permeabilities achieved have still been inadequate, on the order of $10^{-17}-10^{-16} \mathrm{~m}^{2}$. Membranes with improved permeabilities have been produced using materials such as zirconia/titania (Gestel et al., 2006), mineral coal fly ash (Jedidi et al., 2009), Gange river clay (Mittal et al.,

Corresponding Author: Masturi, Department of Physic, Faculty of Mathematics and Natural Science,

Bandung Institute of Technology, Jl Ganeca 10 Bandung 40132, Indonesia 
2011) and Moroccan clay (Palacio et al., 2009), however these materials require complex processing or relatively scarce raw materials, resulting in increased manufacturing costs. The permeability of these membranes is (in other units) $7.11 \times 10^{-12}, 1.32 \times 10^{-9}$, $2.20 \times 10^{-9}$ (in m.s ${ }^{-1} \cdot \mathrm{Pa}^{-1}$ ) and $1.40 \times 10^{-7}$ (in m/sec).

Our goal was to obtain a porous ceramic material with adequate permeability and strength for water purification applications. The filter would be fabricated from clay and coated with titania using simple and lowcost processes. The titania coating was intended to induce photocatalytic activity to degrade pollutants (Badawy et al., 2011; Isnaeni et al., 2011). Both simple mixing and sol-gel methods were investigated. Theoretical models were developed to explain the permeability behavior through the Effective Medium Approximation (EMA) contact model, the strength based on the amount of contact model and the filtration performance from the resistance to fluid flow. Those models are required not only for understanding the mechanism of filters properties emerging physically, but also for obtaining the desired properties of filters in the next fabrication.

\section{MATERIALS AND METHODS}

Clay from Plered (West Java, Indonesia) was used as the main raw material. Polyethylene Glycol (PEG)500000, titania (titanium dioxide) with an average particle size of $200 \mathrm{~nm}$ and Methylene Blue (MB) were purchased from Bratachem (Indonesia).

The clay powder precursor was dried in an oven at $80^{\circ} \mathrm{C}$ for $20 \mathrm{~min}$. Filters were prepared using either a simple mixing or a sol-gel method. In the first process, the clay and PEG were mixed in a container and shaken for $3 \mathrm{~min}$, hot-pressed in a cylindrical mold at $36 \mathrm{MPa}$ pressure and $50^{\circ} \mathrm{C}$ temperature for 20 min, then fired at $900^{\circ} \mathrm{C}$ for $14 \mathrm{~h}$. In the sol-gel process, the clay and PEG were stirred in $40 \mathrm{~mL}$ of water for 10 minutes using a high-speed mixer and then dried by sun exposure for approximately two days to produce a PEG-containing clay composite. This material was mechanically crushed to obtain a fine powder. The powder was hot-pressed in a cylindrical mold at $36 \mathrm{MPa}$ and $50^{\circ} \mathrm{C}$ for $20 \mathrm{~min}$ and then fired at $900^{\circ} \mathrm{C}$ for $14 \mathrm{~h}$. The PEG/clay ratio was altered to modify the permeability, strength and filtration performance of the filters. The sol-gel filters were coated with titania by dry mixing various ratios of PEG and titania. The fabricated samples were $4 \mathrm{~cm}$ in diameter and approximately 3.8-4.3 $\mathrm{mm}$ thick depending on the clay/PEG content.

The porosity was performed using BET measurement with Nova Quantachrome Instrument with nitrogen as absorbate gas. Using the BET equation and $\mathrm{BJH}$ analysis of isotherm graph of $\mathrm{N}_{2}$ adsorptiondesorption to relative pressure, the surface area, porosity and mean pore size of the samples could be obtained.

The permeability was measured using the apparatus illustrated in Fig. 1. Darcy's law (Matyka et al., 2008) states that $\mathrm{Q}=\mathrm{kA} \Delta \mathrm{P} /(\mu \Delta \mathrm{L})$, where $\mathrm{Q}$ is the volumetric flow rate, $\mathrm{k}$ is the filter permeability, $\mathrm{A}$ is the filter surface area, $\Delta \mathrm{P}$ is the pressure difference between the two filter surfaces, $\mu$ is the dynamic viscosity of the fluid and $\Delta \mathrm{L}$ is the filter thickness. In these tests hydrostatic pressure was employed, so $\Delta \mathrm{P}=$ $\operatorname{pg} \Delta \mathrm{h}$, where $\mathrm{p}$ and $\Delta \mathrm{h}$ are the density and height of the fluid. Darcy's law may be rearranged to obtain the permeability $\mathrm{k}=\mathrm{Q} \mu \Delta \mathrm{L} /\left(\operatorname{Apg} \Delta \mathrm{h}\right.$ ) (in units of $\left.\mathrm{m}^{2}\right)$. The permeability may also be expressed in other units using a modified expression, such as:

$\mathrm{Q}=\mathrm{kA} \Delta \mathrm{h} / \Delta \mathrm{L}$

Where:

$\mathrm{k}=\mathrm{kpg} / \mu\left(\right.$ in $\left.\mathrm{m} \mathrm{sec}^{-1}\right)$, or $\mathrm{Q}=\mathrm{k}^{\prime} \mathrm{A} \Delta \mathrm{p}$

Where:

$\mathrm{k}^{\prime}=\mathrm{k} /(\mu \Delta \mathrm{L})($ in $\mathrm{m} / \mathrm{Pa} . \mathrm{s})$ :

Compressive strength measurements were performed according to ASTM C0109M-02 using a Torsee Tokyo Testing Machine MFG Ltd. equipped with a load cell. The contact area was $1600 \mathrm{~mm}^{2}$.

Simulated wastewater was prepared by dissolving Methylene Blue (MB) in water at a concentration of $32.735 \mu \mathrm{M}$. Flow tests were performed under Tube-Lamp (TL) light illumination of approximately 160 Lux to induce MB degradation through the titania catalyst. The filtration performance was measured using UV-Vis spectroscopy (NanoCalc-2000 spectrometer) to determine the concentration of methylene blue before and after filtration (Grishchuk, 1971). The filter retention is defined as the ratio of methylene blue remaining in the filtered water to the initial concentration. This value may be used to obtain the filter rejection, which is defined as the ratio of concentration of methylene blue removed by the filter to the initial concentration (Zhang et al., 2006; Schafer et al., 2000).

SEM and SEM-EDX analysis were performed using a JEOL JSM 6510LA Analytical Scanning Microscope to investigate the chemical composition of the clay raw material, its particle size and the filter surface morphology. The porosity was measured using a High Speed Gas Sorption Analyzer NOVA 2200. 
Am. J. Environ. Sci., 8 (2): 79-94, 2012

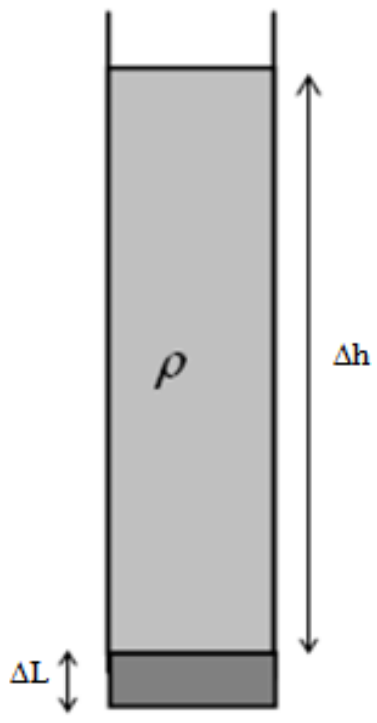

Fig. 1: Permeability test schematic

\section{RESULTS}

The particle size of Plered clay and its chemical composition were examined using SEM and EDS analysis respectively. It was obtained that the particle size is about $5.3 \mu \mathrm{m}$ (Fig. 2a), meanwhile, the most prevalent materials were $\mathrm{SiO}_{2}\left(54.49 \%\right.$ wt) and $\mathrm{Al}_{2} \mathrm{O}_{3}$ $(27.20 \% \mathrm{wt})$, along with several metal oxides such as $\mathrm{FeO}, \mathrm{MgO}, \mathrm{TiO}_{2}, \mathrm{Na}_{2} \mathrm{O}, \mathrm{K}_{2} \mathrm{O}$ and a smaller amount of non-metal oxides such as $\mathrm{SO}_{3}$ (Fig. 2b). Clay is composed of hydrated aluminium silicate $\left(\mathrm{Al}_{2} \mathrm{O}_{3} \cdot x \mathrm{SiO}_{2} . n \mathrm{H}_{2} \mathrm{O}\right)$. From the composition of $\mathrm{SiO}_{2}$ and $\mathrm{Al}_{2} \mathrm{O}_{3}$ above, the weight ratio of $\mathrm{Al}$ to $\mathrm{Si}$ of the used clay is about 1:1 that is near to kaolinite clay (Ding et al., 2009). Even though silica and alumina are dominant compounds of clay, the presence of other compounds is very reasonable since the clay was directly taken from the environment.

From BET measurement it was found that the $\mathrm{N}_{2}$ adsorption-desorption isotherm of the sol gel (SG) filters (Fig. 3a) shows a type-II isotherm. The BET surface area of SG1, SG2, SG3, SG4 and SG5 is 21.881, 22.137, $24.183,22.113$ and $21.824 \mathrm{~m}^{2} \mathrm{~g}^{-1}$ respectively and the total pore volume of them is $0.104,0.105,0.109,0.096$ and $0.106 \mathrm{~cm}^{3} \mathrm{~g}^{-1}$. The Pore Size Distribution (PSD) of all samples calculated from the desorption branch of the isotherm using the BJH method is $3.57 \mathrm{~nm}$ in average. Similar to sol gel filters, the isotherm graph of simple mixing (SM) filters (Fig. 3b) is also a type-II graph with BET surface area of SM1, SM2, SM3, SM4 and SM5 is 26.711, 21.518, 22.557, 26.838 and $25.954 \mathrm{~m}^{2} \mathrm{~g}^{-1}$ respectively.

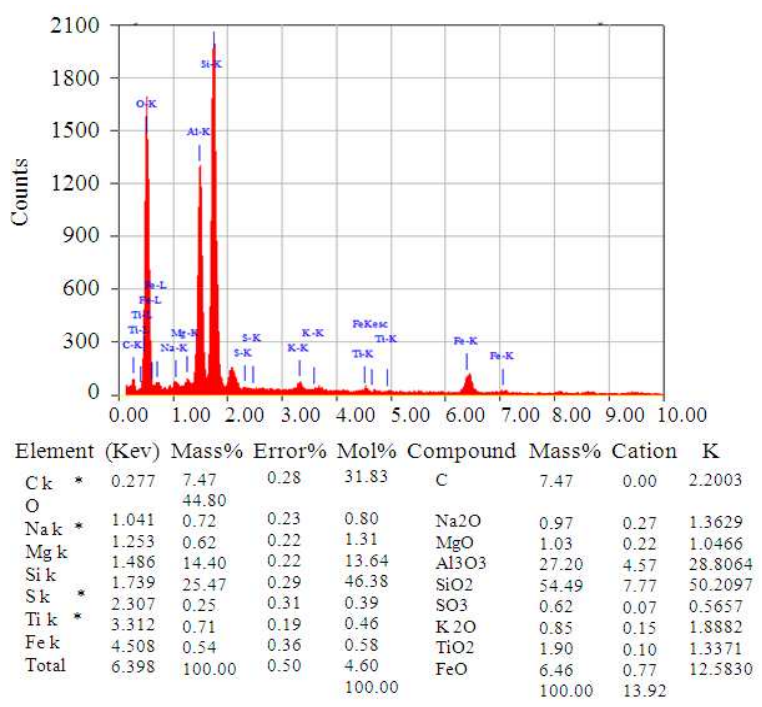

(a)

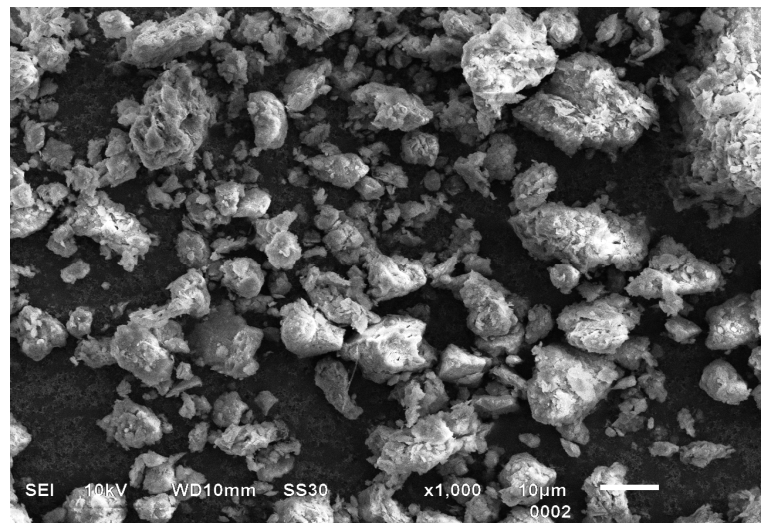

(b)

Fig. 2:(a) SEM image of clay particles and it was obtained the mean particles size about $5.3 \mu \mathrm{m}$, (b) EDS analysis of Plered clay to obtain its composition. It was obtained the main compounds are silica (54.49\%) and alumina $(27.20 \%)$ that close to kaolinite. The bar length is $10 \mu \mathrm{m}$

Table 1:Mean pore size and porosity of the filters for sol gel and simple mixing process

\begin{tabular}{lcl}
\hline Sample & Mean pore size $(\mathrm{nm})$ & Porosity $(\%)$ \\
\hline SG1 & 3.40 & 24.25 \\
SG2 & 3.40 & 24.86 \\
SG3 & 3.82 & 27.25 \\
SG4 & 3.40 & 32.20 \\
SG5 & 3.80 & 36.89 \\
SM1 & 3.40 & 35.83 \\
SM2 & 3.79 & 39.66 \\
SM3 & 3.80 & 42.64 \\
SM4 & 3.40 & 47.95 \\
SM5 & 3.41 & 49.16 \\
\hline
\end{tabular}




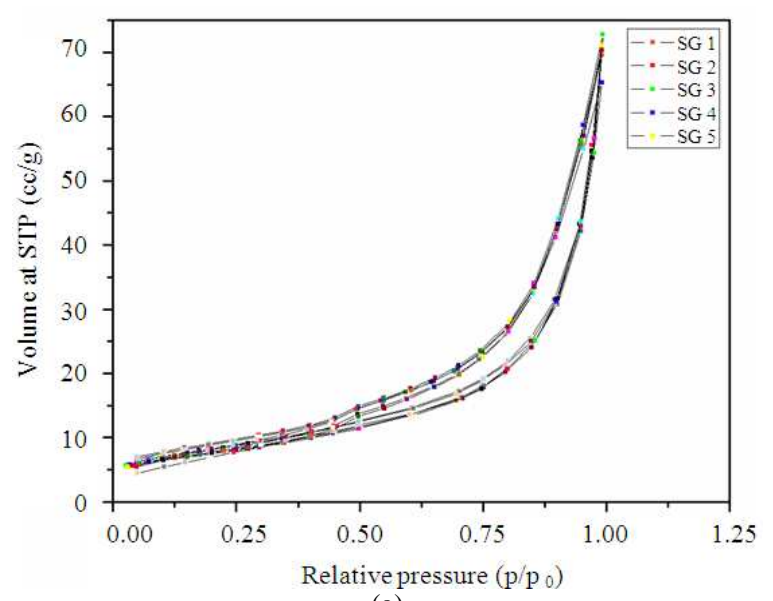

(a)

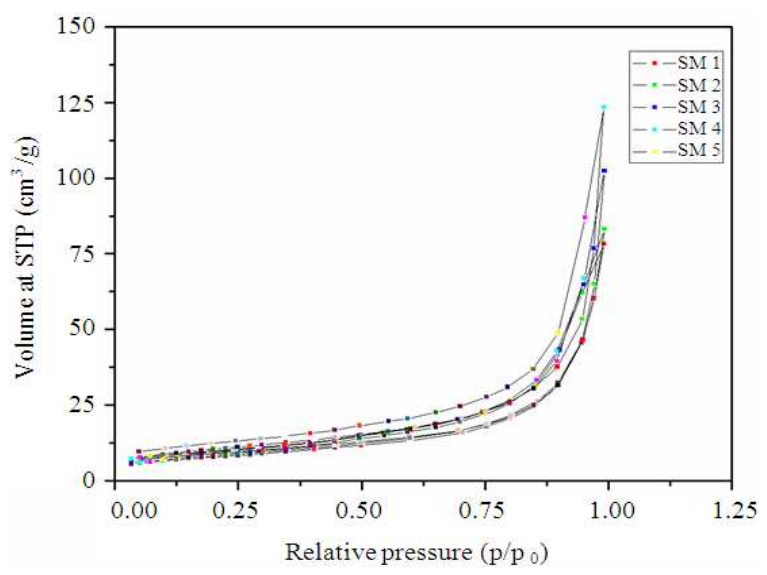

(b)

Fig. 3: Volume of gas sorbed during $\mathrm{N}_{2}$ adsorption and desorption plotted to relative pressure for: (a) sol gel and (b) simple mixing process. The indexes $1,2,3,4$ and 5 of both figures denote samples with clay/PEG compositions (w/w) are 9.5:0.5, 9:1, 8.5:1.5, 8:2 and 7.5:2.5

Meanwhile, the total pore volume of the filters is $0.117,0.123,0.154,0.184$ and $0.154 \mathrm{~cm}^{3} \mathrm{~g}^{-1}$ and the PSD averagely is $3.56 \mathrm{~nm}$ (Table 1). This suggests that the filters of both methods are mesoporous types (Spanoudaki et al., 2005).

\section{DISCUSSION}

The filters have same mean pore size for both simple mixing and sol gel processes, meanwhile the porosities are different even though for same composition of clay and PEG (Table 1) where for simple mixing process, the filters porosity is larger than that of sol gel. (For SM1 sample the porosity is $35.83 \%$ meanwhile for SG1 sample, its porosity is $24.25 \%$ and so on).

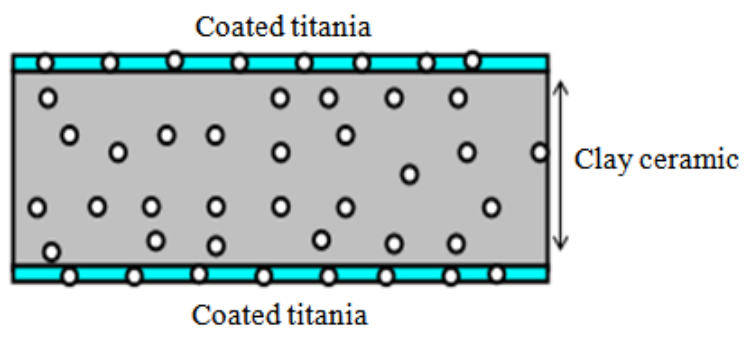

Fig. 4: Illustration of present filter

These can be explained as follow. In the simple mixing process, the arrangement of the particles yields the larger spaces since the particle size of clay and PEG is larger. Beside that, since PEG is in powder form, there is no coverage of PEG to the clay that narrows the spaces between them. Instead, by sol gel process, their size is smaller and the PEG covers the clay more perfectly since its form is gel. Even though the firing process reduces the pore size as sintering process (Putyra et al., 2008), the simple mixing process ultimately yields larger porosity than that of sol gel.

The similar of mean pore size of both methods is guessed due to the heat (temperature and duration) applied to the samples tends to saturated values so that the size of pores after sintered is near constant.

For sol-gel coated titania, for simplicity the porosity could be considered as porosity of sol-gel without titania due to far smaller of coated-part fraction and thickness compared to clay inside (Fig. 4).

The filter permeability was determined from the results of flow tests performed using water containing $32.735 \mu \mathrm{M} \mathrm{MB}$ under 160 Lux room illumination. The permeability of the sol-gel filters generally was lower than the filters produced by simple mixing for the equal fraction of PEG, not for equal porosity. Even, for lower porosity, the permeability of sol gel otherwise was higher than that of simple mixing. It was not a strange phenomenon because in sol Gel Process, the Polymer (PEG) has covered the clay and by hot-pressing process the coverage connected each other to form connected pores after fired. Otherwise, in simple mixing even though hot-pressed, the polymer coverage was very minimal, so that the connecting of pores occurred minimally too. However, in higher PEG volume fraction, the connected pores of simple mixing was more due to increasing amount of PEG powder connected each others. As result, its permeability is larger than that of sol gel.

Interestingly, the permeability improved (particularly at higher porosities) when the titania coating was applied to the sol-gel filters (Fig. 5a). 


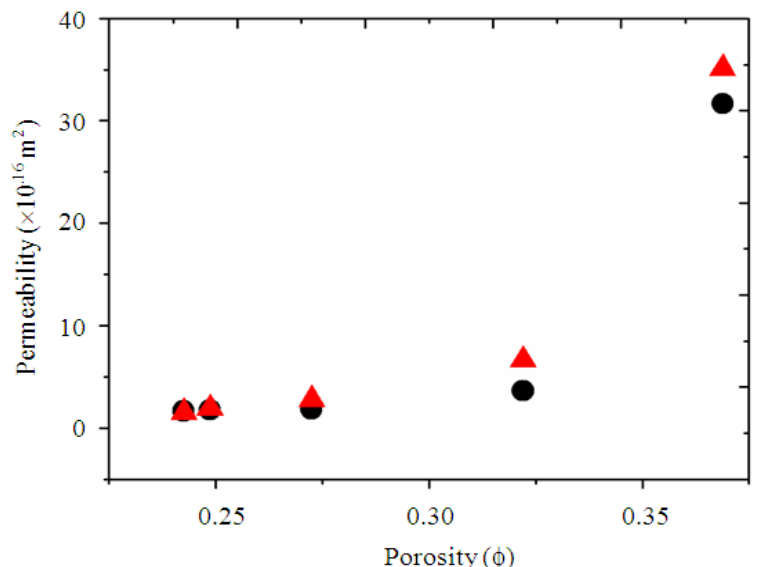

(a)

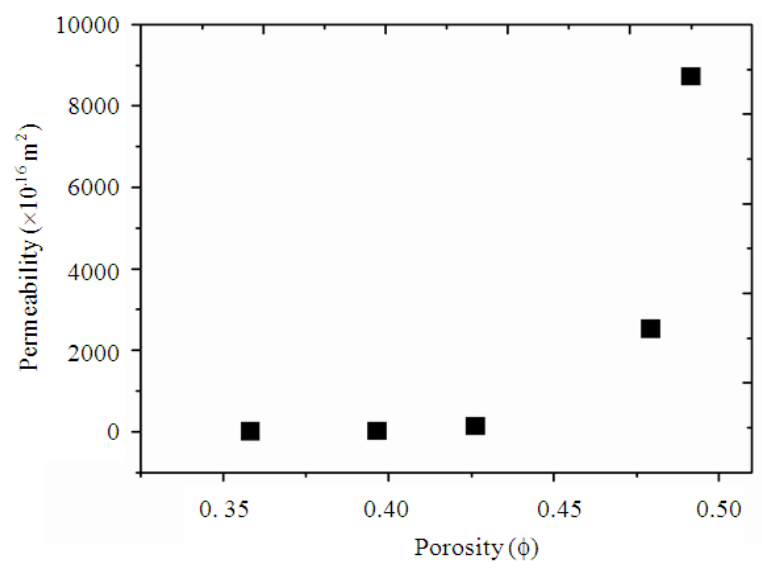

(b)

Fig. 5: Filter permeability as a function of porosity of: (a) sol-gel filters without (black circles) and with (red triangles) titania, (b) simple mixing filters

Filters without titania have a thickness governed by the pressure and temperature during hot pressing and the PEG/clay composition ratio. Since the pressure and temperature were held constant, the clay/PEG composition was the dominant factor affecting thickness. When a filter with a certain composition was coated with titania, the thickness would slightly increase and the permeability would change depending on the permeability of the titania coating.

This was confirmed during examination of SEM images. Before coating with titania the filters exhibited a dense and irregular pore structure (Fig. 6a), otherwise, as the titania coating was applied by simply mixing the titania and PEG powders, after titania was coated to the filters surface, the pore structure was more regular and visible (Fig. 6b). Beside that, the titania permeability was far greater than that of the clay ceramic and ultimately the total average permeability was higher as well.

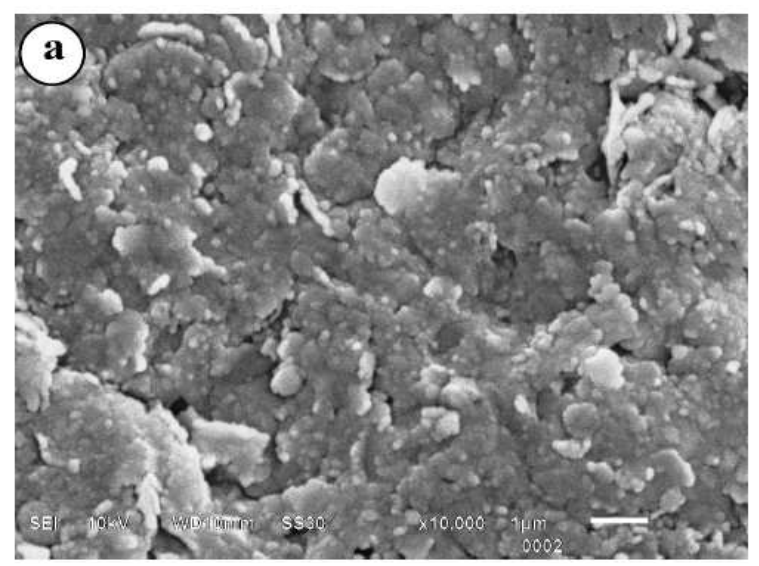

(a)

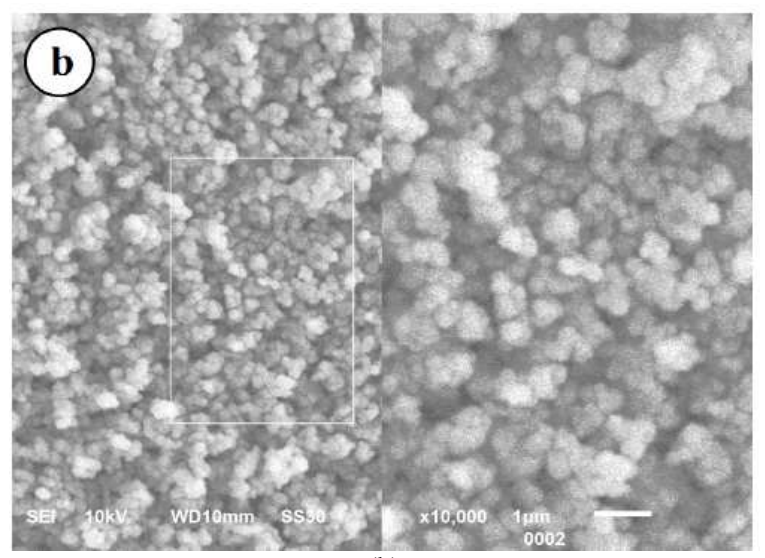

(b)

Fig. 6: Surface microstructure of sol-gel filter (a) before and (b) after coating with titania. The bar length is $1 \mu \mathrm{m}$

However, the permeability of the filters before and after titania incorporation tended to remain the same (Fig. $5 a)$, possibly due to the far smaller thickness of the titania coating relative to the clay filter. The increased permeability at higher porosities may also be explained by noting that at higher porosity, the thickness is slightly lower due to the smaller fraction of solids, making the titania contribution to the average permeability slightly greater (Fig. 5a).

The sol-gel process yielded filters with permeabilities of $1.65-31.57 \times 10^{-16} \mathrm{~m}^{2}$ for uncoated filters and $1.49-34.99 \times 10^{-16} \mathrm{~m}^{2}$ for titania-coated filters. These values are comparable to or better than previously produced filters such as Tunisian clay with a maximum permeability of $3.95 \times 10^{-17} \mathrm{~m}^{2}$ (Hamdi and Srasra, 2008) or alumina with a permeability of $6.99 \times 10^{-16} \mathrm{~m}^{2}$ (Biesheuvel, 1999). Filters produced by simple mixing had permeabilities 
Am. J. Environ. Sci., 8 (2): 79-94, 2012

of $1.38 \times 10^{-16} \mathrm{~m}^{2}-8.72 \times 10^{-13} \mathrm{~m}^{2}$, equivalent to $3.96 \times 10^{-11} \mathrm{~m} \mathrm{~Pa} . \mathrm{sec}^{-1}$ (or $\left.1.55 \times 10^{-9} \mathrm{~m} \mathrm{sec}\right)^{-1}$ )$2.50 \times 10^{-7} \mathrm{~m} \mathrm{~Pa} . \mathrm{sec}^{-1}$ (or $9.82 \times 10^{-6} \mathrm{~m} \mathrm{sec}^{-1}$ ). These filters therefore display adequate permeation. They are substantially improved compared to zirconia/titania membranes $\left(7.11 \times 10^{-12} \mathrm{~m} \mathrm{sec}^{-1} . \mathrm{Pa}\right)$ (Gestel et al., 2006), ceramics produced from mineral coal fly ash $\left(1.32 \times 10^{-9} \mathrm{~m} \mathrm{~Pa} \cdot \mathrm{sec}^{-1}\right)($ Jedidi et al., 2009), Moroccan clay filters $\left(1.40 \times 10^{-7} \mathrm{~m} \mathrm{sec}^{-1}\right)$ (Palacio et al., 2009) and Gange river clay filters $\left(2.20 \times 10^{-9} \mathrm{~m} \mathrm{~Pa} \mathrm{sec}^{-1}\right)$ (Mittal et al., 2011).

Generally, the permeability increases with porosity due to improved fluid flow. However, for low values porosity of sol gel the increase in permeability was very small until a critical value was reached, i.e., $32.20 \%$ (Fig. $5 a)$, after which it sharply increased. Similar behavior was observed in filters produced by mixing, where the increase in permeability occurred porosity of $42.64 \%$ (Fig. 5b). At this critical point, a sufficient number of pores are formed that extend across the thickness of the membrane. This is similar to the electrical conductivity phenomenon known as percolation in which the conductivity rises sharply at a point referred to as the percolation threshold $\left(\dot{\emptyset}_{\mathrm{c}}\right)$. This has been used to successfully explain the electrical conductivity of electrolyte polymers (Mikrajuddin et al., 1999).

Prior to firing, the clay samples were brittle since they consisted of weakly-associated individual particles. Several important stages occur during firing. When the temperature reaches $100^{\circ} \mathrm{C}$, the ceramic undergoes evaporation of loosely-bound water. Since PEG has a flash point of $182-287^{\circ} \mathrm{C}$ (Priatama et al., 2010), firing at that temperature for two $h$ ensures decomposition and evaporation of PEG from the ceramic to form pores. When the sample is fired at $900^{\circ} \mathrm{C}$ for five $\mathrm{h}$, the clay particles sinter and bond to produce a strong and hard porous ceramic (Putyra et $a l ., 2008)$. The firing also affects in reducing the pore size. It can be seen on the same of the simple mixing and the sol gel pore size. It is guessed that the pore size of the simple mixing filters that previously large becomes small and ultimately close to pore size of the sol gel filters.

The strength and hardness of ceramics are controlled by the porosity and strength decreases with increasing porosity. The ceramic strength is also increased on a microscopic scale by formation of ionic and covalent bonding networks. The principal compounds in clay materials are silica and alumina. These compounds has important role in ceramic strength (Baccour et al., 2009) since they and other metal oxides contained in the clay such as $\mathrm{Fe}_{2} \mathrm{O}_{3}, \mathrm{MgO}$, $\mathrm{TiO}_{2}, \mathrm{Na}_{2} \mathrm{O}$ and $\mathrm{K}_{2} \mathrm{O}$ govern the formation of ionic bonds. Covalent bonds occur between silica and nonmetal oxides such as $\mathrm{SO}_{3}$ (Brown et al., 2007).

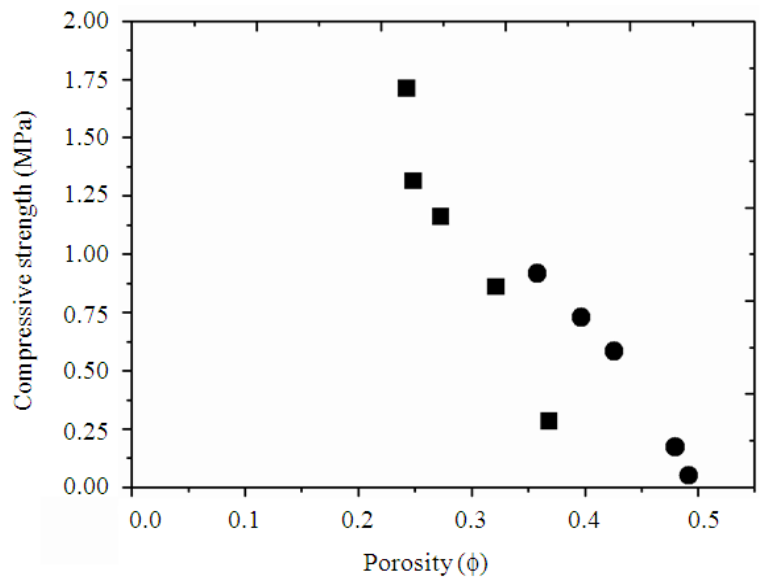

Fig. 7: Strength of sol-gel (squares) and simple mixing (circles) filters as function of porosity

The strength of ceramics originates from contact interactions among the particles to form bonds. As the amount of contact increases, the strength increases. When the porosity is very low the amount of contact and the strength are maximized. This correlates with the strength data presented in Fig. 7, in which there is a significant loss of strength at higher porosities. This also confirms that sol gel filters strength is higher than to that of simple mixing where in simple mixing the porosity tends to be higher. As proposed by Kumar and Bhattacharjee (2003) that strength of porous medium was affected by porosity and mean pore size. With identical mean pore size of the simple mixing and sol gel filters, the strength is dominated by porosity and particle arrangement that will be discussed in mathematical approach of this study.

The goal of filter design is to produce a filter with adequate permeability while still maintaining strength. For sol-gel filters, strength of $1.16 \mathrm{MPa}$ was achieved at a porosity of $27.25 \%$, while for simple mixing filters the strongest is a filter with porosity of $35.83 \%$ with the strength is $0.92 \mathrm{MPa}$ (Fig. 7). Meanwhile, the adequate strength is $0.73 \mathrm{MPa}$ for a porosity of $39.66 \%$. It appears that from a strict permeability standpoint the mixing process is better than the solgel process. However, filters require adequate strength to at least withstand the hydrostatic pressure of the fluid and the sol-gel process provides filters that are stronger for a given permeability.

The filter performance was measured by comparing the concentration of methylene blue in the simulated wastewater using UV-Vis spectroscopy before and after filtration (Grishchuk, 1971). 
Am. J. Environ. Sci., 8 (2): 79-94, 2012

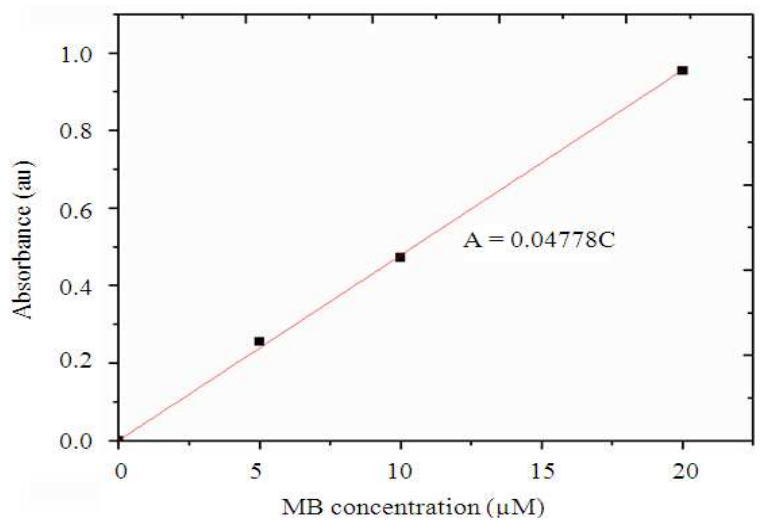

Fig. 8: Calibration curve for methylene blue concentration

The relationship between absorbance and methylene blue (MB) concentration is described in the calibration curve of Fig. 8 and may be directly determined from the equation $\mathrm{A}=0.04778 \mathrm{C}$, where $\mathrm{A}$ and $\mathrm{C}$ are the maximum absorbance occurred (au) and $\mathrm{MB}$ concentration $(\mu \mathrm{M})$. Maximum absorbance occurred at a wavelength of $663 \mathrm{~nm}$. Fig. 9 is a plot of the absorbance of the solutions before and after filtration using several filter types.

For sol-gel filters, the MB concentration remaining after filtration under a hydrostatic pressure of $4 \mathrm{kPa}$ increased with increasing permeability, from $0.98 \%$ of initial concentration for the lowest permeability to $1.44 \%$ for the highest permeability (Fig. 10). The same trend was observed in filters produced by mixing, in which $1.50-38.05 \%$ of the dye remained depending on permeability. The improved performance of the sol-gel filters is likely the result of their lower permeability.

The reduction of pollutant concentrations following filtration is defined as the rejection $(\mathrm{Rj})$ since it is equivalent to the material rejected from the filter (Schafer et al., 2000), whereas the amount of pollutant remaining after filtration is defined as the retention (Rt) (Zhang et al., 2006). These quantities are related by:

$R j+R t=1$

where:

$$
R j=\left(1-\frac{C_{p}}{C_{i}}\right)
$$

and:

$$
\mathrm{Rt}=\frac{\mathrm{C}_{\mathrm{p}}}{\mathrm{C}_{\mathrm{i}}}
$$

where $\mathrm{C}_{\mathrm{i}}$ and $\mathrm{C}_{\mathrm{p}}$ are the $\mathrm{MB}$ concentrations in the water before and after filtration.

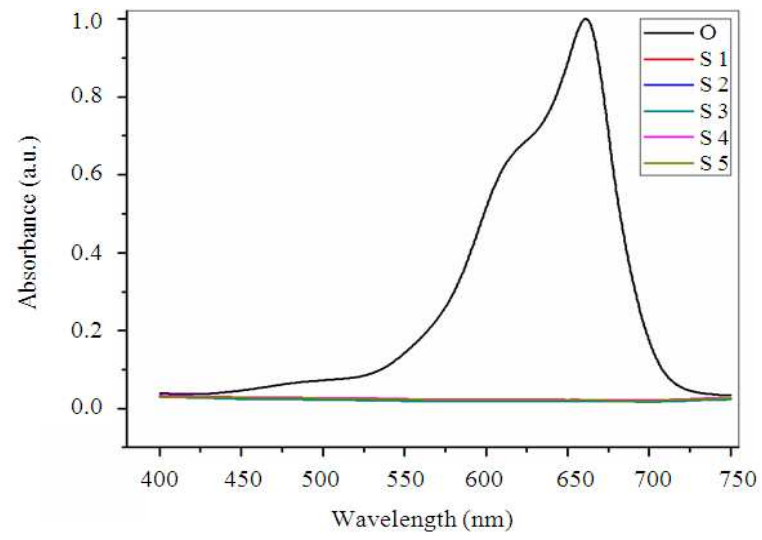

(a)

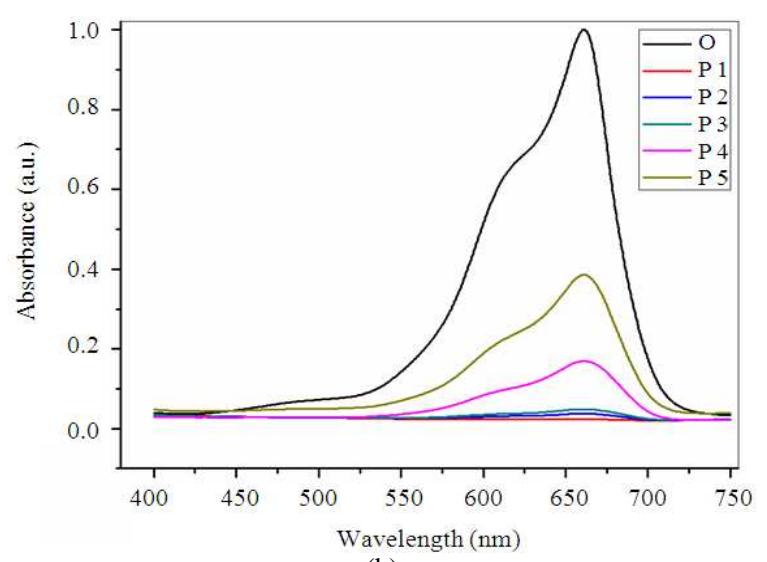

(b)

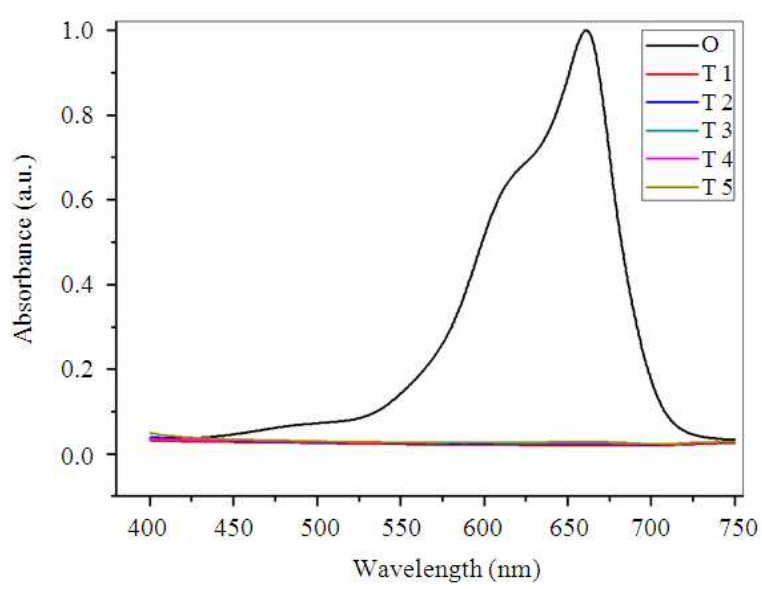

(c)

Fig. 9:Comparison between absorbance of solutions before $(\mathrm{O})$ and after filtration $(1,2,3,4$ and 5 correspond to porosity of $24.25 \%, 24.86 \%$, $27.25,32.20$ and $36.89 \%$ for both sol gels and $35.83,39.66,42.64,47.95$ and $49.16 \%$ for simple mixing) for: (a) sol-gel, (b) simple mixing, (c) sol-gel coated with titania 


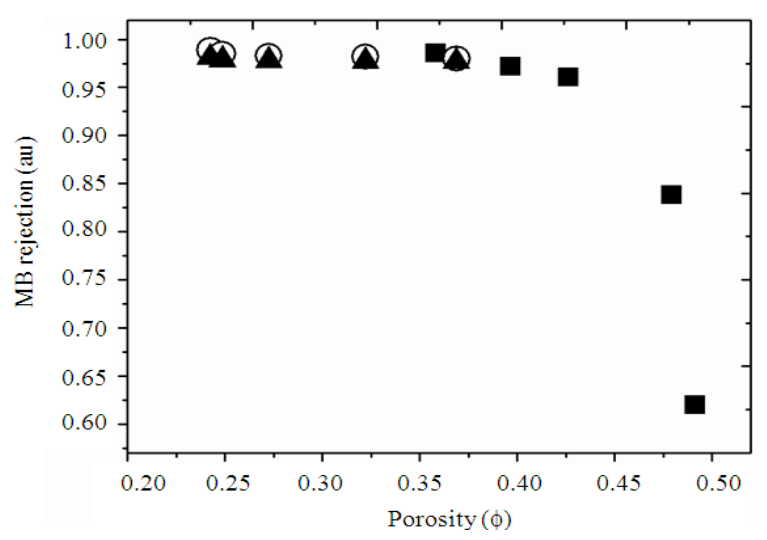

Fig. 10:MB rejection as function of porosity for: simple mixing (black squares), uncoated solgel filters (black triangles) and sol-gel filters coated with titania (blank circles)
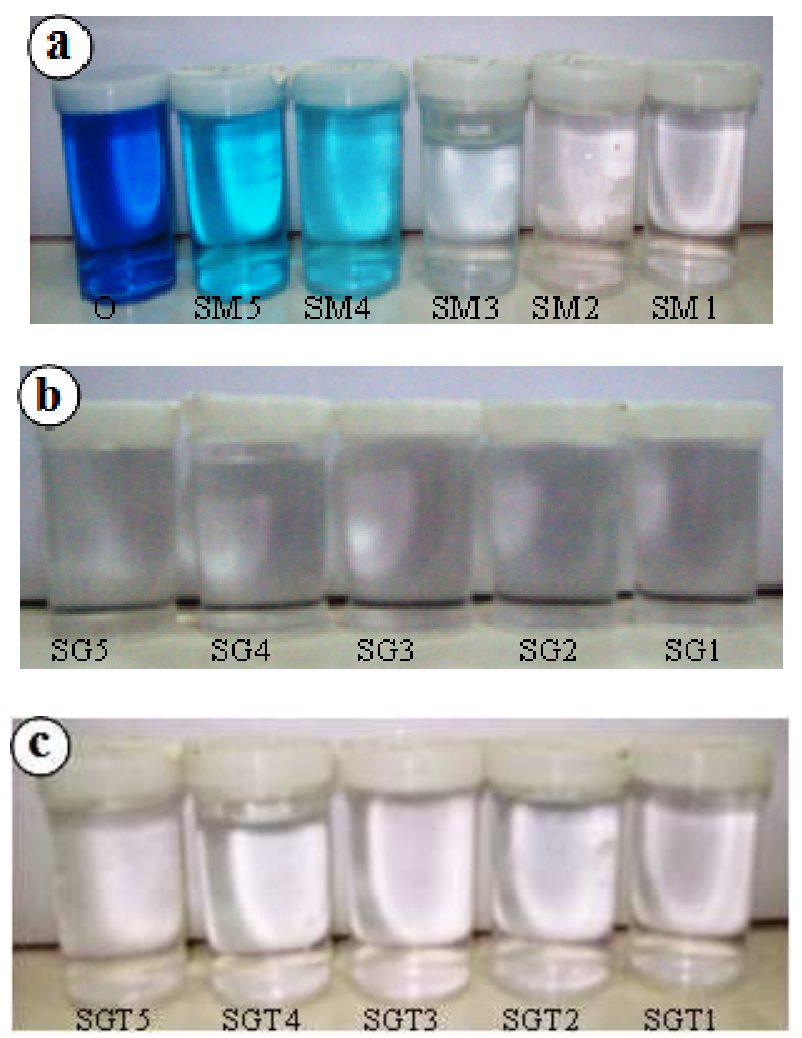

Fig. 11:Water samples after filtration using (a) filters produced by simple mixing, (b) uncoated solgel filters and (c) sol-gel filters coated with titania. $\mathrm{O}$ in (a) denotes water before filtration and the indexes 1,2,3,4 and 5 in all figures denote porosity of $35.83 \%, 39.66$, $42.64,47.95$ and $49.16 \%$ for simple mixing and $24.25,24.86,27.25,32.20$ and $36.89 \%$ for both sol gels
If a decomposition process is simultaneously occurring in the filter (for instance due to photocatalytic activity) the rejection may be written as Eq. 2:

$\mathrm{Rj}=\left(1-\frac{\mathrm{C}_{\mathrm{p}}}{\mathrm{C}_{\mathrm{i}}}\right)=\frac{\mathrm{C}_{\mathrm{pf}}+\mathrm{C}_{\mathrm{d}}}{\mathrm{C}_{\mathrm{i}}}$

Where:

$\mathrm{C}_{\mathrm{pf}}=$ The pollutant amount physically removed

$\mathrm{C}_{\mathrm{d}}=$ The amount decomposed through decomposition

For titania-coated sol-gel filters, the rejection ranged from $98.89-97.98 \%$ depending on permeability (Fig. 10). Since the permeability increased with the titania coating, it would be expected that the rejection would decrease. The fact that this did not occur supports the occurrence of catalytic activity. However, since the rejection in the absence of the titania coating approached a saturation value near $98 \%$, the effect of the coating was less than $1 \%$ and was dwarfed by the overall reduction. To obtain a more accurate value for the rejection due to photocatalytic activity, it would be necessary to perform Dissolved Oxygen (DO) and Chemical Oxygen Demand (COD) measurements (Badawy et al., 2011). These may be the subject of future work.

If the filters are operated under higher pressures, the effect of titania addition becomes more visible. The volumetric flow rate of the fluid through the filter depends on the pressure differential (Matyka et $a l ., 2008)$ and the rejection decreases with increasing flow rate ((Schafer et al., 2000). As the physical rejection is decreased, the effects of photochemical degradation become more apparent.

As far, the adequate filter of sol-gel (without titania) is that with $1.84 \times 10^{-16} \mathrm{~m}^{2}, 1.16 \mathrm{MPa}$ and $97.80 \%$ of permeability, strength and rejection respectively. Meanwhile, for simple mixing it was one with porosity of $39.66 \%$ that its permeability, strength and rejection are $1.25 \times 10^{-16} \mathrm{~m}^{2}, 0.73 \mathrm{MPa}$ and $97.13 \%$ respectively. From these results we claimed the filterproduced was very effective to filter pollutant from the water, especially for MB pollutant as one of the main textile pollutants in several industrial cities. Even, for sol-gel coated titania, the adequate filter undergoes in increasing permeability and rejection to $2.7610^{-16} \mathrm{~m}^{2}$ and $98.30 \%$ respectively.

Images of water samples before and after filtration are provided in Fig. 10. For filters produced by simple mixing, the MB color was still visible, particularly for porosity of 47.95 and $49.16 \%$ (Fig. 11a). For sol-gel filters with and without titania coating, all samples appeared clear upon visual inspection (Fig. 11b and 11c). 
Another advantage of titania incorporation is in filter reusability. After several uses, the filters became stained due to dye retention. Catalytically active filters could be restored by exposure to sunlight for several days (Fig. 12). However, over extended periods the filters may become clogged by extensive deposits of material (Zhao et al., 2005). In this case, the filters may be regenerated by firing at high temperatures to burn off organic contaminants.

Mathematical approach: Fluid flow in porous media may be described using Darcy's law: $\mathrm{Q}=\kappa \mathrm{A} \Delta \mathrm{P} / \mu \Delta \mathrm{L}$ where $Q$ is the volumetric flow rate of the fluid. It is analogous to current flow in electricity: $\mathrm{I}=\sigma \mathrm{A} \Delta \mathrm{V} / \Delta \mathrm{L}$ and where $\kappa / \mu$ in the fluid plays a role similar to $\sigma$ in electrical calculations and we may use the Effective Medium Approximation (EMA) of conductivity to explain the permeability of porous materials (Mikrajuddin and Khairurrijal, 2009; Lorenz and Persson, 2010).

Porous materials are composed of a solid portion and pores and there are three types of contact: porepore, solid material-solid material and pore-solid material. When fluid flows in a porous material it experiences resistance to flow in the form of porepore, solid material-solid material and pore-solid material resistances. These may be generally formulated as: $\mathrm{R}=\Delta \mathrm{P} / \mathrm{Q}$ (Mikrajuddin and Khairurrijal, 2009). The concept of resistance is useful in explaining some phenomena such as thremal conductivity of the nanofluids (Masturi et al., 2011a). Particularly, the fluid resistance is very important in explaining pollutant filtration performance and it will be discussed later in this study. From the resistance of each type of contact, the average permeability may be determined.

Suppose that $\mathrm{k}_{1}$ and $\mathrm{k}_{2}$ are the pore permeability and solid material permeability, where, $\mathrm{k}_{1}>>\mathrm{k}_{2}$. In each cell, the three contact probabilities may be obtained from Eq. 3-5 (Mikrajuddin et al., 1999):

$$
\begin{aligned}
& \mathrm{P}_{\mathrm{pp}}=\alpha\left(\frac{\varphi_{\mathrm{p}}}{\mathrm{f}}\right)^{2} \\
& \mathrm{P}_{\mathrm{mm}}=\left(1-\frac{\varphi_{\mathrm{p}}}{\mathrm{f}}\right)^{2} \\
& \mathrm{P}_{\mathrm{pm}}=2(1-\alpha)\left(\frac{\varphi_{\mathrm{p}}}{\mathrm{f}}\right)\left(1-\frac{\varphi_{\mathrm{p}}}{\mathrm{f}}\right)
\end{aligned}
$$

where, $\alpha$ is fraction of pores connected each others $\dot{\emptyset}_{\mathrm{p}}$ and $f$ are the porosity and packing fraction of the lattice ( $\mathrm{f} \cong 0.52$ for simple cubic, $\mathrm{f} \cong 0.68$ for body centered cubic (bcc) and $\mathrm{f} \cong 0.74$ for face centered cubic (fcc) and hexagonal close packed (hcp)), so the effective permeability becomes Eq. 6:

$$
\begin{aligned}
& \alpha\left(\frac{\varphi}{\mathrm{f}}\right)^{2} \frac{\mathrm{k}_{\mathrm{pp}}-\mathrm{k}_{\mathrm{e}}}{\mathrm{k}_{\mathrm{pp}}+\left(\frac{\mathrm{z}}{2}-1\right) \mathrm{k}_{\mathrm{e}}}+\left(\frac{1-\varphi}{\mathrm{f}}\right)^{2} \frac{\mathrm{k}_{\mathrm{mm}}-\mathrm{k}_{\mathrm{e}}}{\mathrm{k}_{\mathrm{mm}}+\left(\frac{\mathrm{z}}{2}-1\right) \mathrm{k}_{\mathrm{e}}}+ \\
& 2(1-\alpha)\left(\frac{\varphi}{\mathrm{f}}\right)\left(\frac{1-\varphi}{\mathrm{f}}\right) \frac{\mathrm{k}_{\mathrm{pm}}-\mathrm{k}_{\mathrm{e}}}{\mathrm{k}_{\mathrm{pm}}+\left(\frac{\mathrm{z}}{2}-1\right) \mathrm{k}_{\mathrm{e}}}=0
\end{aligned}
$$

Where:

$\mathrm{k}_{\mathrm{pp}}=$ The average permeability of two pores in contact

$\mathrm{k}_{\mathrm{mm}}=$ The average permeability of two solid materials in contact

$\mathrm{k}_{\mathrm{pm}}=$ The average permeability of pores in contact with solid material and $\mathrm{z}$ is the coordination number, or the number of nearest neighbor particles in the lattice structure used, so that $z=6$ for $\mathrm{sc}, \mathrm{z}=8$ for bcc and $\mathrm{z}=12$ for fcc and hcp

For two pores in contact, the resistance is a serial summation of a porous bulk resistance $\left(R_{b p}\right)$ and a constriction resistance $\left(R_{c}\right)$ (Fig. 13), making the total resistance Eq. 7:

$\mathrm{R}_{\mathrm{p}}=\mathrm{R}_{\mathrm{bp}}+\mathrm{R}_{\mathrm{c}}$

where, regardless of the total resistance, the average permeability is the pore permeability $\left(\mathrm{k}_{\mathrm{p}}\right)$.

For solid materials in contact, the total resistance (Fig. 14) is the solid material resistance Eq. 8:

$\mathrm{R}_{\mathrm{mm}}=\mathrm{R}_{\mathrm{m}}=\frac{1}{\mathrm{k}_{\mathrm{m}}} \frac{\mathrm{d}}{\mathrm{d}^{2}}=\frac{1}{\mathrm{k}_{\mathrm{m}} \mathrm{d}}$

and the solid material permeability $\left(\mathrm{k}_{\mathrm{m}}\right)$ is the average solid-solid permeability.

For pore-solid material contacts, the total resistance may be described as a network of resistances (Fig. 15) Since $\left(\frac{1}{2} R_{m}, R_{m}{ }^{\prime}\right)>>R_{b p}$, the total resistance of a poresolid contact (for a single cell) may be simplified as Eq. 9:

$\mathrm{R}_{\mathrm{pm}} \cong \frac{1}{2} \mathrm{R}_{\mathrm{m}}$

and the average permeability is $2 \mathrm{k}_{\mathrm{m}}$. 

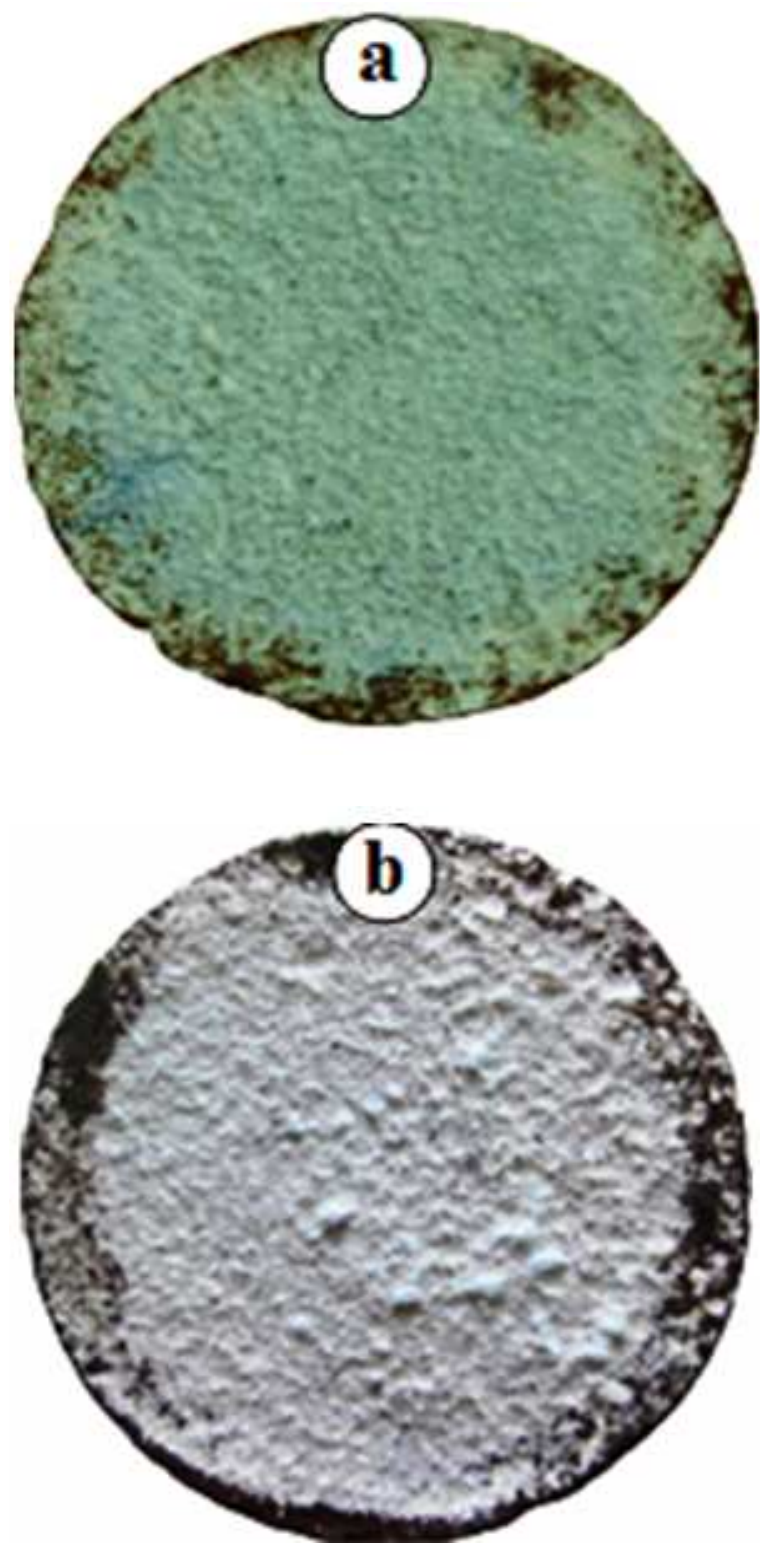

Fig. 12:Filter after several uses: (a) before exposure to sunlight, (b) after exposure to sunlight for 3 days

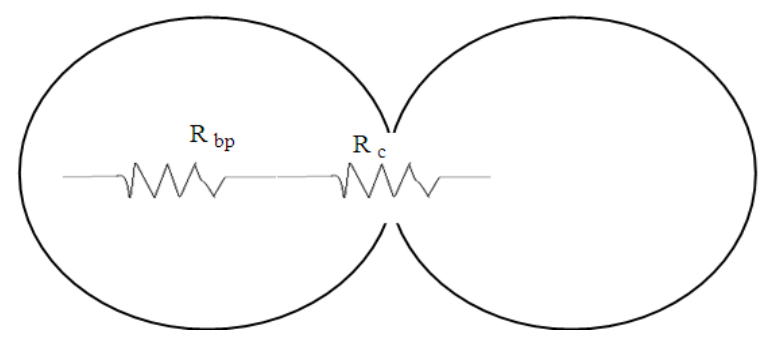

Fig. 13: Resistance in pore-pore cell

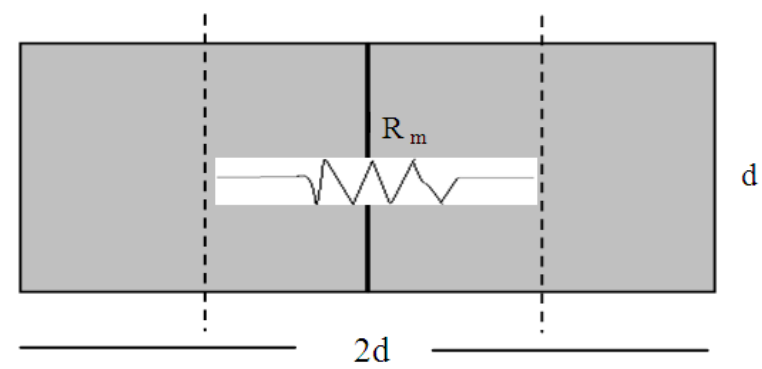

Fig. 14: Resistance of solid-solid contact cell

The dependence of permeability on mean pore size is described by the relation Eq. 10:

$k=\operatorname{cd}^{2} f(\varphi)$

where, $\mathrm{c}$ is a constant and $d$ is the pore diameter (O'Brien et al., 2007; Lorenceau et al., 2009). To obtain the single pore permeability $\left(\mathrm{k}_{\mathrm{sp}}\right)$ where the porosity is unity, we propose Eq. 11:

$\mathrm{k}_{\mathrm{sp}}=\mathrm{c} \overline{\mathrm{A}}$

Where:

$\mathrm{c}=\mathrm{A}$ dimensionless constant that depending on many parameters

$\overline{\mathrm{A}}=$ The average area of a sphere capable of passing through the pore, that is $\overline{\mathrm{A}}=\frac{\pi}{6} \overline{\mathrm{D}}_{\text {rms }}^{2}$

For porous medium such as filter with total surface area $A_{t}$ and surface density of pores $n$, once again we propose the pores surface permeability $\left(\mathrm{k}_{\mathrm{p}}\right)$ as Eq. 12:

$\mathrm{k}_{\mathrm{p}}=\mathrm{cnA}_{\mathrm{t}} \overline{\mathrm{A}}$

This assumption is in agreement with the fact that increased pore cross-sectional area provides easier fluid flow, which results in greater permeability. Eq. 12 may be written as Eq. 13:

$\mathrm{k}_{\mathrm{p}}=\frac{\pi}{6} \mathrm{cnA}_{\mathrm{t}} \mathrm{d}_{\mathrm{rms}}{ }^{2}=\mathrm{CnA}_{\mathrm{t}} \mathrm{d}_{\mathrm{rms}}{ }^{2}$

In which $\mathrm{C}$ is another constant and $\mathrm{d}_{\mathrm{ms}}$ is the root mean square pore diameter obtained from $\mathrm{BJH}$ analysis of the BET measurement.

From the BET measurement above, $\mathrm{d}_{\mathrm{ms}}-\mathrm{sm}=\mathrm{d}_{\mathrm{ms}-\mathrm{sg}}=$ $3.56 \mathrm{~nm}, \mathrm{n}_{\mathrm{sm}}=8.43 \times 10^{15} \mathrm{~m}^{-2}, \mathrm{~m}^{-2}, \mathrm{~A}_{\mathrm{t}}=8.04 \times 10^{-2} \mathrm{~m}^{2}$ and assume $\mathrm{c}=1$, therefore, it was obtained $\mathrm{k}_{\mathrm{p}-\mathrm{sm}}=$ $4.51 \times 10^{-5} \mathrm{~m}^{2}$ and $\mathrm{k}_{\mathrm{p}-\mathrm{sg}}=4.51 \times 10^{-5} \mathrm{~m}^{2}$. 
Am. J. Environ. Sci., 8 (2): 79-94, 2012

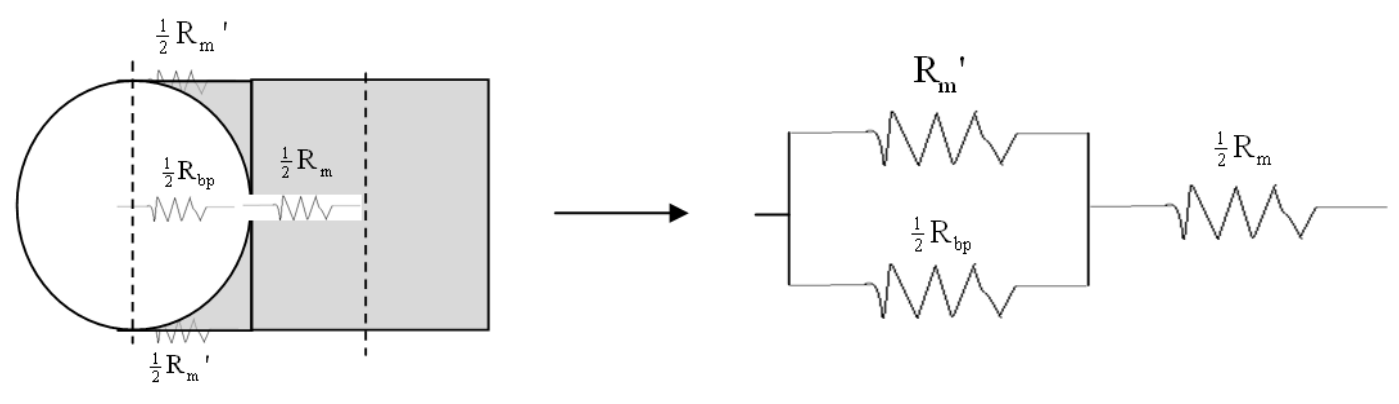

Fig. 15: Resistance of pore-solid material contact cell

Thus Eq. 6 becomes Eq. 14:

$$
\begin{aligned}
& \alpha\left(\frac{\varphi}{f}\right)^{2} \frac{\mathrm{k}_{\mathrm{p}}-\mathrm{k}_{\mathrm{e}}}{\mathrm{k}_{\mathrm{p}}+\left(\frac{\mathrm{z}}{2}-1\right) \mathrm{k}_{\mathrm{e}}}+\left(\frac{1-\varphi}{\mathrm{f}}\right)^{2} \\
& \frac{\mathrm{k}_{\mathrm{m}}-\mathrm{k}_{\mathrm{e}}}{\mathrm{k}_{\mathrm{m}}+\left(\frac{\mathrm{z}}{2}-1\right) \mathrm{k}_{\mathrm{e}}}+ \\
& 2(1-\alpha)\left(\frac{\varphi}{\mathrm{f}}\right)\left(\frac{1-\varphi}{\mathrm{f}}\right) \frac{2 \mathrm{k}_{\mathrm{m}}-\mathrm{k}_{\mathrm{e}}}{2 \mathrm{k}_{\mathrm{m}}+\left(\frac{\mathrm{z}}{2}-1\right) \mathrm{k}_{\mathrm{e}}}=0
\end{aligned}
$$

The difference threshold of sol gel and simple mixing above (Fig. 16) indicated that their pores arrangement (cell) is different. For sol gel filters where the percolation threshold is about $32 \%$, it was shown that the appropriate cell is a fcc or hcp cell with fraction of pores connected each others to generate permeability is about $40 \%$. In other word, the pores fraction of $60 \%$ did not generate permeability since they did not connect each other, otherwise, connected with clay particles.

Otherwise, for simple mixing, with percolation threshold is about $40 \%$ the appropriate cell is simple cubic with fraction of connected pores is less (20\%). It can be accepted by understanding that in powder form of PEG as pores former, the probability of their connection to generate permeability is less than to that of sol gel form. In sol gel form, all of clay particles have been covered by PEG that connected each others during hot-pressing process, however, during firing process, the pores size tends to reduce. As result, some of them do not connect with their neighbours.

The accordance of percolation phenomena was further confirmed by scaling relation: $k_{e}=k_{p}\left(\phi-\phi_{c}\right)^{t}$ with $\phi$ is porosity near porosity threshold $\left(\phi_{c}=39.66 \%\right.$ and $\phi_{\mathrm{c}}=32.20 \%$ for simple mixing and sol gel filters respectively) and obtained $t=1.25$ and $t=1.30$ for both methods respectively. These values were close to the accepted value of approximately 1.2 (Mikrajuddin and Khairurrijal, 2009).
A simple contact model was employed to explain the filter compressive strength based on the following assumptions:

The strength of the filter is governed by solid material contacts. In conditions where the porosity is zero, the amount of solid contact is at a maximum and the maximum strength is achieved. This assumption was combined with another approach to successfully explain the compressive strength of composites (Masturi et al., 2011b).

Increasing pore fraction decreases contact among the particles. As the porosity increases, the contact among the particles decreases. At ascertain porosity, the strength will approach zero.

Suppose that for certain porosity, $\phi$, the amount of omitted contact due to the porosity is $y$. if porosity increases as $\mathrm{d} \phi$, the omitted contact increases as dy. For simplicity, the addition of omitted contact is proportional to the additional of porosity and amount of omitted contact, so:

$\mathrm{dy}=\operatorname{Cyd} \varphi$

with $\mathrm{C}$ is a dimensionless constant. The Eq. 15 can be easily solved as Eq. 16:

$\mathrm{y}=\mathrm{e}^{\mathrm{C}\left(\varphi-\varphi_{\mathrm{c}}\right)}$

with $\phi_{\mathrm{c}}$ is critical porosity, i.e., porosity when strength is zero and $C$ dimensionless constant depends on several parameters. As a model proposed by Kumar and Bhattacharjee (2003) that Eq. 17:

$$
\sigma=\frac{\operatorname{Bf}(\varphi)}{\sqrt{r_{m}}}
$$

Where:

$\begin{aligned} \sigma & =\text { Compressive strength } \\ \mathrm{B} & =\text { constant }\end{aligned}$ 


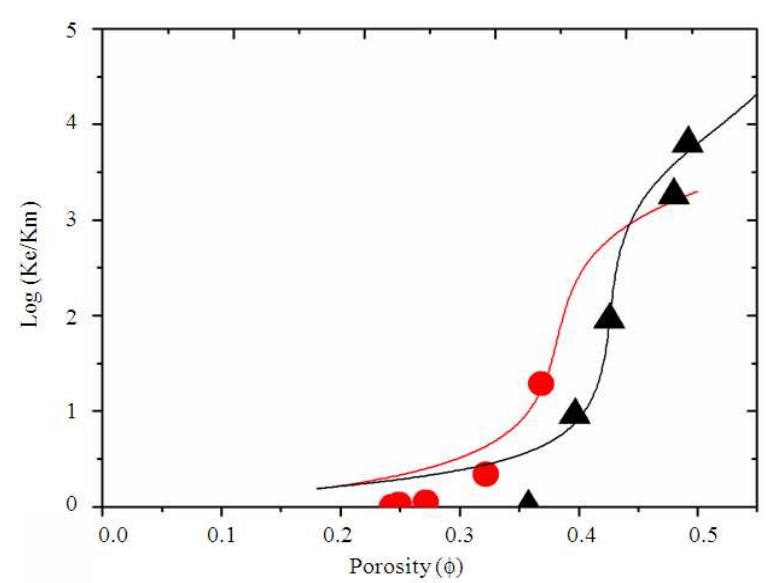

(a)

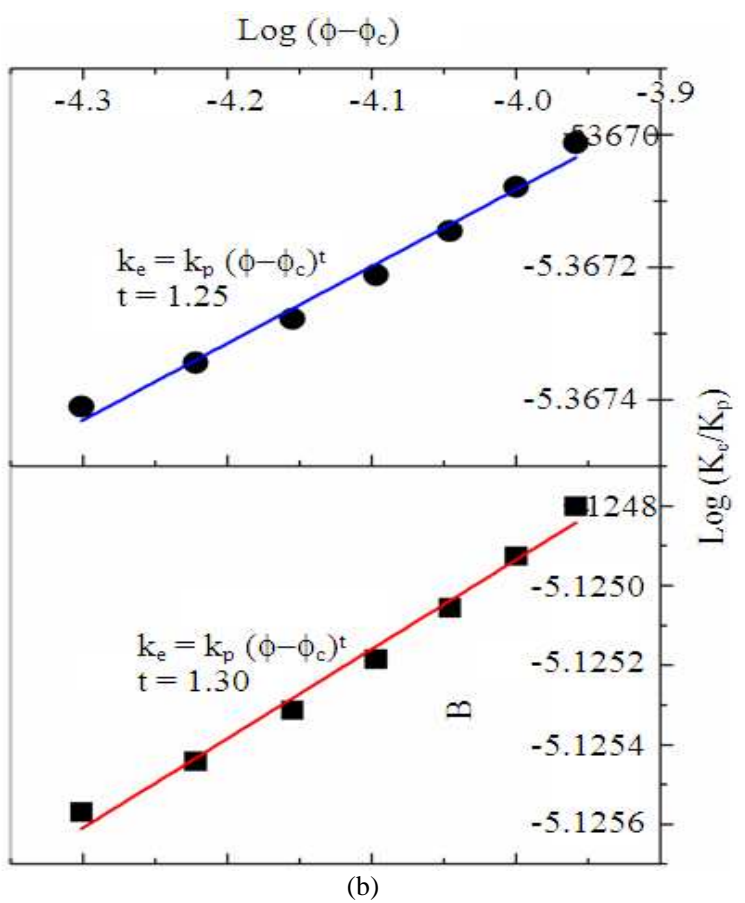

Fig. 16: (a-b) Filters permeability as a function of porosity. The symbols represent experimental data, where red circle and black triangle are sol gel and simple mixing filters respectively. The curves represent the model calculation, where the red line for sol gel with: $\mathrm{k}_{\mathrm{p}} / \mathrm{k}_{\mathrm{m}}=10000, \mathrm{z}=12, \mathrm{f}=$ $0.74, \alpha=0.4$ and the black line for simple mixing with: $\mathrm{k}_{\mathrm{p}} / \mathrm{k}_{\mathrm{m}}=10^{6}, \mathrm{z}=6, \mathrm{f}=0.52, \alpha=0.2$, The percolation thresholds are $32.20 \%$ and $39.66 \%$ for sol gel and simple mixing respectively; (b) Scaling relation of percolation threshold of sol gel filters near $\varphi_{c}=32.20 \%$ and obtained $t=1.25$ (upper graph) and simple mixing filters near $\varphi_{\mathrm{c}}=39.66 \%$ and obtained $\mathrm{t}=1.30$ (bottom graph) $r_{m}=$ Mean pore radii of pores and assume that compressive strength of ceramic satisfies:

$\sigma=\sigma_{\mathrm{m}}-\sigma^{\prime}$

Where:

$\sigma_{\mathrm{m}}=$ Maximum strength

$\sigma^{\prime}=$ Strength omitted due to porosity, with $\sigma^{\prime}=\sigma_{\mathrm{m}} \mathrm{y}$ Eq. 22 could be expressed as Eq. 18:

$\sigma=\frac{\mathrm{B}}{\sqrt{\mathrm{r}_{\mathrm{m}}}}\left[1-\mathrm{e}^{\left(\varphi-\varphi_{\mathrm{c}}\right)}\right]$

By exponential fitting of the data using Mathematica ${ }^{\circledR}$ software with the built up equation above and remembering the mean pores diameter of both filters is $3.56 \mathrm{~nm}$, it was obtained: $\mathrm{B}=0.0002755$, $\chi_{\mathrm{c}}=0.5056$ for simple mixing and $\mathrm{B}=0.0004462 \chi_{\mathrm{c}}=$ 0.3982 for sol gel. It was also obtained the strength of simple mixing and sol gel filters for zero porosity ( 0) were 2.79 and $3.47 \mathrm{MPa}$ respectively, meanwhile the critical porosity of both filters were $50.56 \%$ and $39.82 \%$ respectively.

The filter performance (the filter rejection described in Fig. 17) may be modeled with the following assumptions:

The filter performance is governed by the "conductance" of the fluid passing through the pores, defined as: $\chi=1 / \mathrm{R}$, where $\mathrm{R}$ is the fluid resistance in the filter. The amount of pollutant removed decreases with increasing conductance.

The filtered concentration at any point depends on the current concentration at that point.

For simplicity, we assume that the mean surface area of the pores is constant and the decrease in concentration $\mathrm{dC}$ is proportional to the increment of filter conductance $\mathrm{d} \chi$ and the current concentration, $\mathrm{C}$, so Eq. 19:

$\mathrm{dC}=-\beta \mathrm{Cd} \chi$

where, $\beta$ is a filtration constant depending on the difference in pressure across the filter and the fluid viscosity and Eq. 20:

$\mathrm{d} \chi=\mathrm{d}(1 / \mathrm{R})=\mathrm{d}\left(\frac{\mathrm{A}}{1} \mathrm{k}\right)$

where, A and 1 are the surface area and thickness of the filter and are assumed constant for all filters. Equation 19 may be written as Eq. 21:

$\mathrm{dC}=-\mathrm{Cqdk}$ 
that may be easily solved in the form Eq. 22:

$$
\mathrm{C}=\mathrm{C}_{0} \mathrm{e}^{-\mathrm{qk}}
$$

where, $\mathrm{C}_{0}$ is the initial concentration of methylene blue $(32.735 \mu \mathrm{M})$ and $q=\beta A / 1$. Finally, we obtain Eq. 23:

$$
\left.\mathrm{C}=32.735 \mathrm{e}^{-\mathrm{qk}} \text { (in } \mu \mathrm{M}\right)
$$

Using the Mathematica ${ }^{\circledR}$ software to fit the experimental results to this equation, we obtained $\mathrm{q}=$ $0.000926575 \mathrm{~m}^{-2}$ (and $\beta=4.05 \times 10^{-6} \mathrm{~Pa} . \mathrm{s} / \mathrm{m}^{3}$ ) and $\mathrm{q}=$ $0.0000572014 \mathrm{~m}^{-2}$ (and $\beta=2.97 \times 10^{-7} \mathrm{~Pa} . \mathrm{s} / \mathrm{m}^{3}$ ) for solgel and simple mixing filters respectively. From its dimension, it was concluded $\beta$ is the fluid resistance (viscosity) per volume unit along passing the filters. Since the mean pores size obtained from both methods is equal, the 16 -fold difference in $\beta$ values are most likely due to differences in pores arrangement that we have discussed in permeability percolation above. With pores arrangement of simple mixing filters is fcc ( $f=0.74$ and $z=12$ and), their pores densities in every cell are larger so that the resistances are smaller than that of sol gel filters ( $f=0.52$ and $z=6$ ). However, evidence for this requires further discussion and will not be addressed in this study. Nevertheless, based on these values the methylene blue filtration gradient in sol-gel filters is larger (Fig. 18). These plots were expanded to large values of permeability in order to show the fitting trends as decay functions. Table 2 provides a comparison between the experimental and theoretical results.

In addition to permeability, for sol-gel filters coated with titania the filtration performance was also a function of the photocatalytic activity. For simplicity, it is assumed that the fitting equations for sol-gel filters without titania are acceptable since the titania coating is far thinner than the main filter and may be ignored. Suppose the amount of dye decomposed by titania activity is $\mathrm{C}_{\mathrm{t}}$ and depends on the fraction of surface coated with titania, the type and intensity of light illuminating the filter and the effective contact time for decomposition, which is governed by the fluid velocity across the filter surfaces. The fluid velocity is controlled by the pressure differential across the filter and the permeability. The equation for the amount of methylene blue removed becomes Eq. 24:

$\mathrm{C}=32.735 \mathrm{e}^{-\mathrm{qk}}+\mathrm{C}_{\mathrm{t}}(\mathrm{E}, \mathrm{k}, \mathrm{P})$

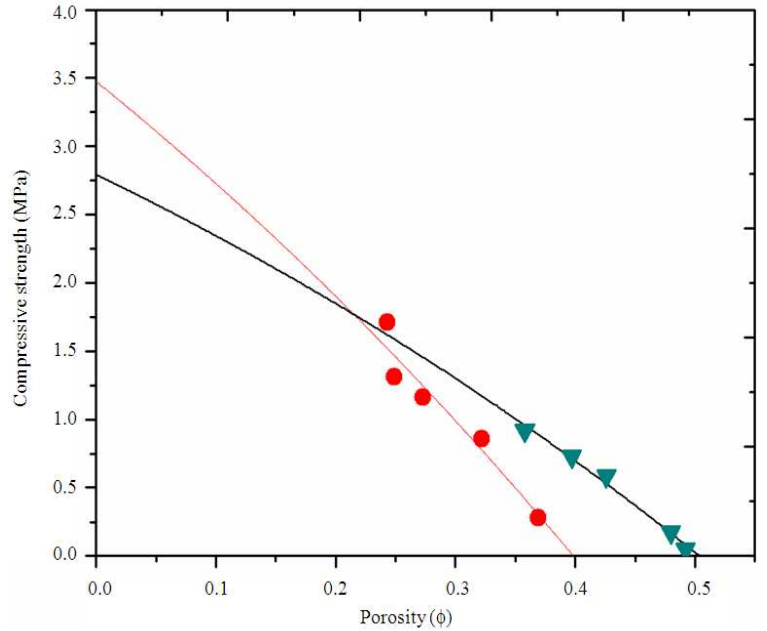

Fig. 17: Strength of filters as function of porosity. Symbols indicate experimental results of simple mixing (triangle) and sol gel (circle). Curves represent mathematical model of simple mixing (black line) and sol gel (red line)

where, $\mathrm{E}, \mathrm{k}$ and $\mathrm{P}$ are the illuminance, permeability and pressure difference. It is difficult to obtain $\mathrm{C}_{\mathrm{t}}(\mathrm{E}, \mathrm{K}, \mathrm{P}$, analytically. In this study the pressure differential and lighting were assumed to be the same for all tests, making $\mathrm{C}_{\mathrm{t}}(\mathrm{E}, \mathrm{K}, \mathrm{P})$ sensitive only to changes in permeability (Table 3 ).

The experimental and theoretical values for $\mathrm{C}_{\mathrm{t}}$ differed at several permeabilities. However, $C_{t}$ decreased as predicted with increasing permeability. The theoretical model predicts that $C_{t}$ would decrease to zero with increasing permeability as the higher fluid velocities reduced the catalyst contact time and rendered the photocatalytic process ineffective. However, the experimental values of $\mathrm{C}_{\mathrm{t}}$ display a maximum, then decrease. This inconsistency might be the result of errors in the curve fitting or possibly because our assumption that the equations used for solgel filters without titania (Eq. 23) are also applicable in filters with the catalyst is inaccurate. This assumption was assumed to be valid because the titania coating thickness is much smaller than the overall filter thickness. However, even though the coating is very thin, the permeability, porosity and mean pore size may be sufficiently different from the bulk filter to cause flow effects. Even so, the assumption above is still acceptable for qualitative descriptions. 
Am. J. Environ. Sci., 8 (2): 79-94, 2012

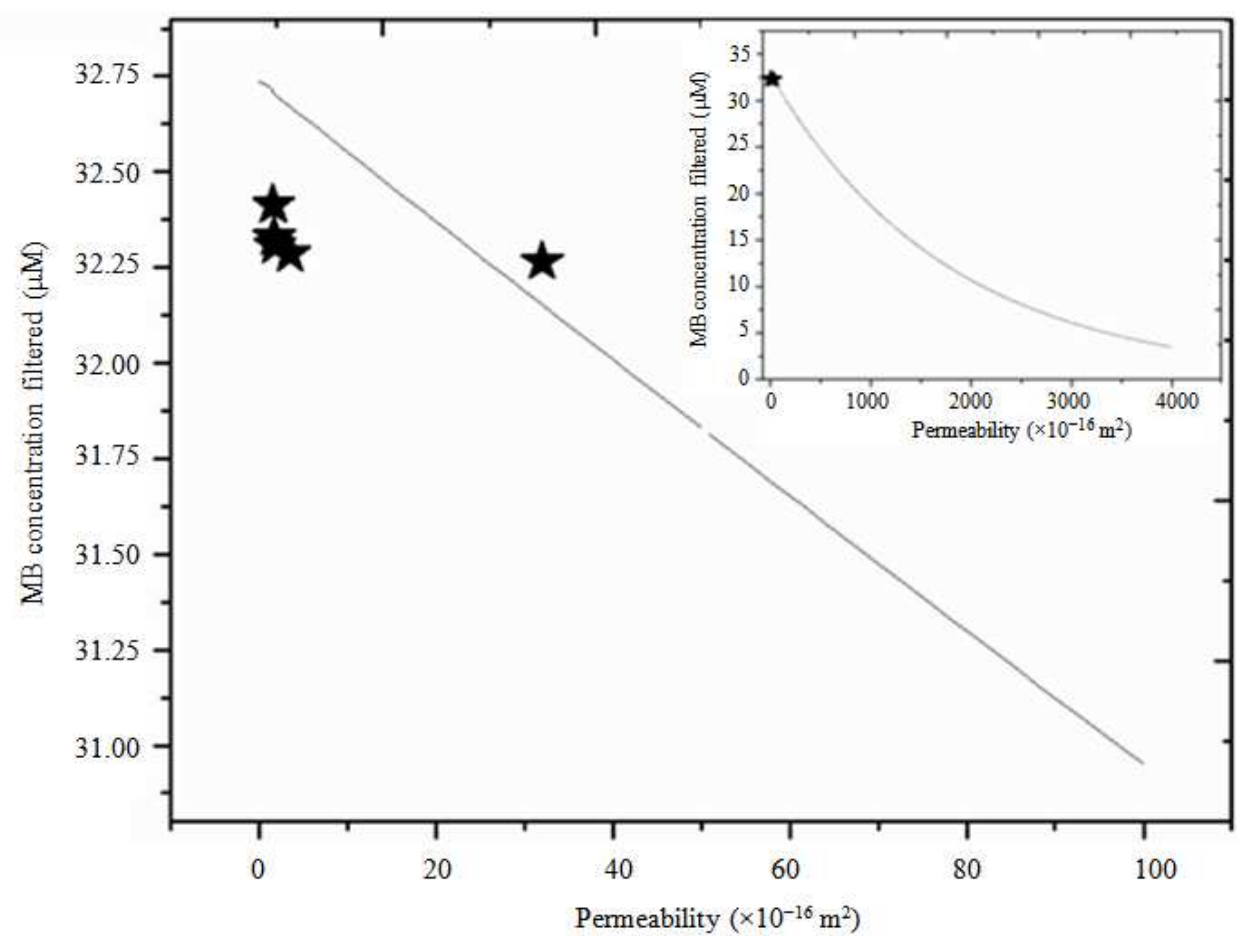

(a)

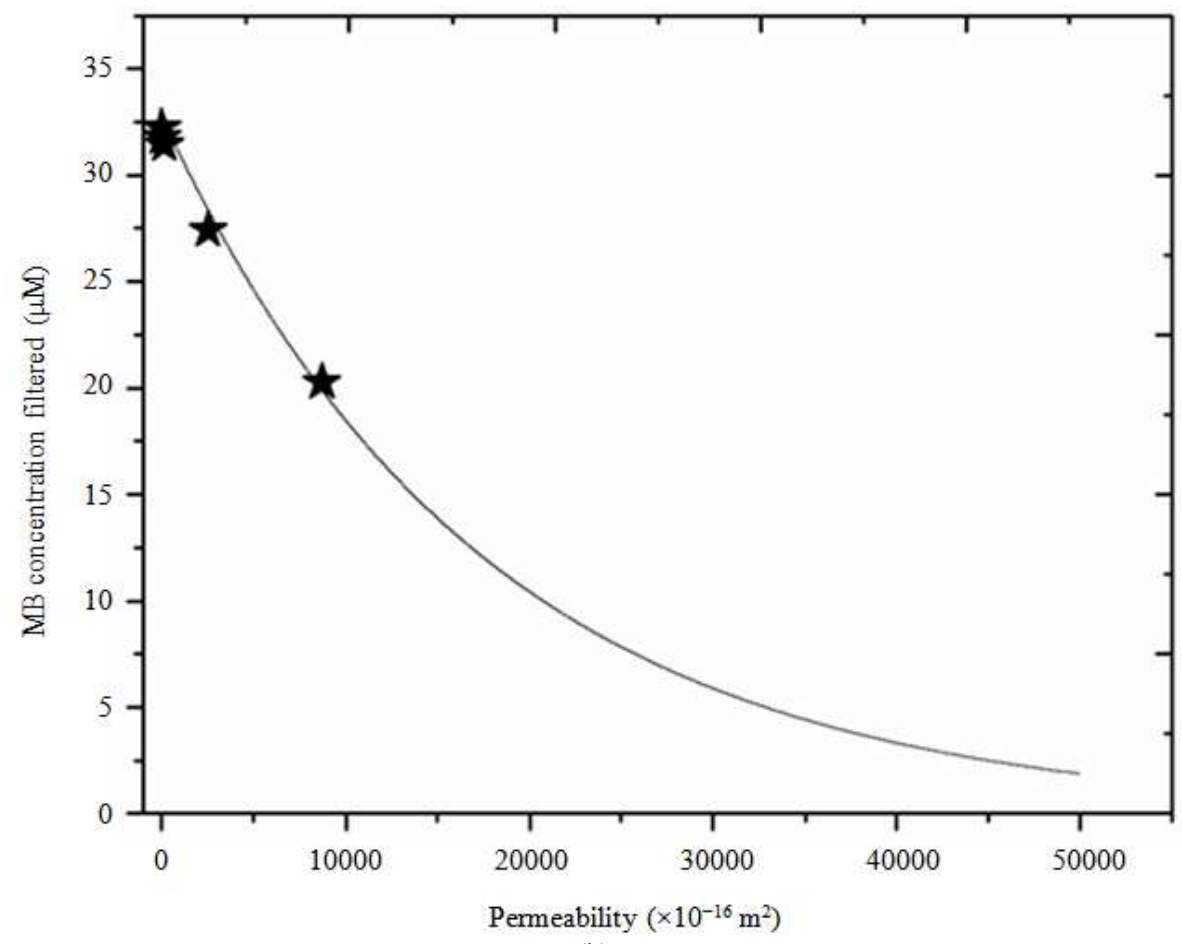

(b)

Fig. 18:MB concentration after filtration using: (a) sol-gel (without titania). Inset: the fitting extrapolation to large permeability; (b) simple mixing filters as a function of permeability. Symbols represent experimental data and curves are theoretical plots 
Am. J. Environ. Sci., 8 (2): 79-94, 2012

Table 2:Comparison between experimental and theoretical permeability and filtration performance results

\begin{tabular}{lllr}
\hline \multirow{3}{*}{ Method } & $\begin{array}{l}\text { Permeability, } \\
\text { Sol-gel }\end{array}$ & $k\left(\times 10^{-16} \mathrm{~m}^{2}\right)$ & MB Concentration Filtered $(\mu \mathrm{M})$ \\
& 1.65000 & 32.414 & Fitting \\
\hline \multirow{5}{*}{ Simple mixing } & 1.75000 & 32.329 & 32.705 \\
& 1.84000 & 32.308 & 32.703 \\
& 3.60000 & 32.286 & 32.701 \\
& 31.5700 & 32.265 & 32.669 \\
& 1.38000 & 32.244 & 32.161 \\
& 12.5100 & 31.795 & 32.732 \\
& 124.290 & 31.432 & 32.712 \\
& 2511.59 & 27.436 & 32.503 \\
& 8724.49 & 20.278 & 28.354 \\
\end{tabular}

Table 3: Comparison of theoretical and experimental values for $C_{t}$

\begin{tabular}{lcr}
\hline Permeability, & $\mathrm{C}_{\mathrm{t}}(\mu \mathrm{M})$ & \\
$\mathrm{k}\left(\mathrm{x} 0^{-16} \mathrm{~m}^{2}\right)$ & Fitting & Experiment \\
\hline 1.49 & 0.318 & 0.252 \\
1.89 & 0.434 & 0.206 \\
2.76 & 0.472 & 0.164 \\
6.61 & 0.398 & 0.141 \\
35.0 & -0.383 & 0.101 \\
\hline
\end{tabular}

\section{CONCLUSION}

Sol-gel and simple mixing processes were used to fabricate titania-coated ceramic membranes for use as wastewater filters. The filter raw materials were clay and PEG, which was used as a pore forming agent. Solutions of methylene blue were used to test the filter performance. Uncoated sol-gel filters exhibited were produced with a permeability of $1.84 \times 10^{-16} \mathrm{~m}^{2}$ and a compressive strength of $1.16 \mathrm{MPa}$ that were capable of reducing the methylene blue concentration to $2.20 \%$ of the initial value at a pressure differential of $4 \mathrm{kPa}$ and an initial $\mathrm{MB}$ concentration of $32.735 \mu \mathrm{M}$. Filters produced using the simple mixing process possessed excellent permeability (up to $8.72 \times 10^{-13} \mathrm{~m}^{2}$ ), but their compressive strength was inadequate, ranging from $0.05 \mathrm{MPa}-0.92 \mathrm{MPa}$. For titania-coated sol-gel filters the permeability was slightly higher than uncoated filters and the rejection was also slightly improved under illumination of approximately 160 Lux. The permeability was modeled using a modified-EMA with contacts approach. The model was in good agreement with the experimental results and matched the scaling relation for percolation with a critical exponent very close to the accepted value. Meanwhile, the strength was modeled using amount of contact approach that also had good accordance to the experimental results. For filtration performance, a new model was developed and the theoretical results closely approximated the experimental results.

\section{ACKNOWLEDGEMENT}

This research was supported by group and innovation research grant (Riset KK dan Inovasi) of Institut Teknologi Bandung (ITB) 2011 and competition grant (Hibah Bersaing) from Universitas Negeri Semarang (UNNES) 2011.

\section{REFERENCES}

Alam, S.M.D.M., T. Kawauchi and T. Takeichi, 2010. Preparation and Characterization of Rigid Polyimide-Clay-Polydimethylsiloxane Hybrid. High Perfor. Polym., 22: 742-760. DOI: 10.1177/0954008309358469

Baccour, H., M. Medhioub, F. Jamoussi and T. Mhiri, 2009. Influence of firing temperature on the ceramic properties of Triassic clays from Tunisia. J. Mater Proces. Technol., 209: 2812-2817. DOI: 10.1016/j.jmatprotec.2008.06.055

Badawy, M.I., M.Y. Ghaly and M.E.M. Ali, 2011. Photocatalytic hydrogen production over nanostructured mesoporous titania from olive mill wastewater. Desalination, 267: 250-255. DOI: 10.1016/j.desal.2010.09.035

Biesheuvel, P.M., 1999. Porous ceramic membranes: suspension processing, mechanical and transport properties and application in the osmotic tensiometer. Inorganic Materials Science.

Brown, T.L., H.E. LeMay Jr. and B.E. Bursten, 2007. Chemistry: The Central Science. 11th Edn., Pearson Prentice Hall, Upper Saddle River, NJ., ISBN: 0136006175, pp: 1117.

Chilingarian, G.V., 1995. Interrelationship among permeability, porosity, specific surface area and irreducible fluid saturation. Sci. Iranica, 1: 9-14.

Ding, S.L., Q.F. Liu and M.Z. Wang, 2009. Study of kaolinite rock in coal bearing stratum, North China. Proc. Earth Plane. Sci., 1: 1024-1028. DOI 10.1016/j.proeps.2009.09.158

Gestel, T.V., H. Kruidhof, D.H.A. Blank and H.J.M. Bouwmeester, 2006. $\mathrm{ZrO}_{2}$ and $\mathrm{TiO}_{2}$ membranes for nanofiltration and pervaporation: Part 1. Preparation and characterization of a corrosionresistant $\mathrm{ZrO}_{2}$ nanofiltration membrane with a MWCO < 300. J. Membrane, Sci., 284: 128-136. DOI: 10.1016/j.memsci.2006.07.020

Grishchuk, M. K., 1971. Use of the Lambert- Beer law in determining the $\mathrm{NO}_{2}$ concentration in the system $\mathrm{N}_{2} \mathrm{O}_{4} \leftrightarrow 2 \mathrm{NO}_{2} \leftrightarrow 2 \mathrm{NO}+\mathrm{O}_{2}$ at high temperatures and pressures. Zhurnal, Prikladnoi, Spektroskopii, 15: 308-313. 
Hamdi, N. and E. Srasra, 2008. Filtration properties of two tunisian clays suspensions: Effect of the nature of clay. Desalination, 220: 194-199. DOI: 10.1016/j.desal.2007.02.037

Hwang, H.J., D.Y. Kim and J. Moon, 2006. Fabrication of porous clay materials with aligned pore structures by freeze-drying. Mater. Sci. Forum, 510-511: 906-909.

Isnaeni, V.A., O. Arutanti, E. Sustini, H. Aliah, Khairurrijal and M. Abdullah, 2011. A novel system for producing photocatalytic titanium dioxide-coated fibers for decomposing organic pollutants in water. Environ. Prog. Sustainable Energy. DOI: 10.1002/ep.10596

Jedidi, I., S. Saidi, S. Khmakem, A. Larbot and N.E. Ammar et al., 2009. New ceramic microfiltration membranes from mineral coal fly ash. Arabian J. Chem., 2: 31-39. DOI: 10.1016/j.arabjc.2009.07.006

Kumar, R. and B. Bhattacharjee, 2003. Porosity, pore size distribution and in situ strength of concrete, Cem. Concr. Res., 33: 155-164. DOI: 10.1016/S0008-8846(02)00942-0

Kuzugudenli, O.E., 2004. Use of pumice stone as a ceramic raw material. Key Eng. Mater., 264-268: 1427-1430.

Lorenceau, E., N. Louvet, F. Rouyer and O. Pitois, 2009. Permeability of aqueous foams. Eur. Phys. J. E. Soft Matter., 28: 293-304. PMID: 19190946

Lorenz, B. and B.N.J. Persson, 2010. Leak rate of seals: Effective-medium theory and comparison with experiment. Eur. Phys. J. E: Soft Matter Biol. Phys., 31: 159-167. DOI: 10.1140/epje/i2010-10558-6

Masturi, M. Abdullah and Khairurrijal, 2011b. High compressive strength of home waste and polyvinyl acetate composites containing silica nanoparticle filler. J. Mater. Cycles Waste Manage., 13: 225231. DOI: 10.1007/s10163-011-0012-2

Masturi, M., E. Sustini, K. Khairurrijal and M. Abdullah, 2011a. Resistors network model of bcc cell for investigating thermal conductivity of nanofluids. AIP Conf. Proc., 1415: 86-89. DOI 10.1063/1.3667227

Matyka, M., A. Khalili and Z. Koza1, 2008. Tortuosityporosity relation in the porous media flow. Phys. Rev. E., 78: 026306-026306. DOI: 10.1103/PhysRevE.78.026306

Mikrajuddin, A. and Khairurrijal, 2009. Gelation model for porosity dependent fluid permeability in porous material. J. Matematika dan. Sains., 14: 15-19.

Mikrajuddin, A., F.G. Shi, S. Chungpaiboonpatana, K. Okuyama and C. Davidson et al., 1999. Onset of electrical conduction in isotropic conductive adhesives: A general theory. Mater. Sci. Semiconductor Proces., 2: 309-319. DOI: 10.1016/S1369-8001(99)00035-9
Mittal, P., S. Jana and K. Mohanty, 2011. Synthesis of low-cost hydrophilic ceramic-polymeric composite membrane for treatment of oily wastewater. Desalination, 282: 54-62. DOI: 10.1016/j.desal.2011.06.071

O’Brien, F.J., B.A. Harley, M.A. Waller, I.V. Yannas and L.J. Gibson et al., 2007. The effect of pore size on permeability and cell attachment in collagen scaffolds for tissue engineering. Technol. Health Care, 15: 3-17. PMID: 17264409

Palacio, L., Y. Bouzerdi, M. Ouammou, A. Albizane and J. Bennazha et al., 2009. Ceramic membranes from Moroccan natural clay and phosphate for industrial water treatment. Desalination, 245: 501-507. DOI: 10.1016/j.desal.2009.02.014

Priatama, A., M. Abdullah, Khairurrijal and $\mathrm{H}$. Mahfudz, 2010. Fabrication of microporous water filter using titanium dioxide particles, silica particles, and polyethylene glycol. ITB J. Eng. Sci., 1: 39-52.

Putyra, P., P. Kurtyka, L. Jaworska, M. Podsiadlo and B. Smuk, 2008. The Analysis of strength properties of ceramic performs for infiltration process. Arch. Mater. Sci. Eng., 33: 97-100.

Schafer, A.I., A.G. Fane and T.D. Waite, 2000. Fouling effects on rejection in the membrane filtration of natural waters. Desalination, 131: 215-224. DOI: 10.1016/S0011-9164(00)90020-1

Selvaganapathi, A., M. and Alagar, P. Gnanasundaram and A. Gedanken, 2010. Preparation of siloxanemodified tetraglycidyl epoxy-clay nanocomposites - its thermal and morphological properties. J. Compo. Mater., 44: 543-557. DOI: 10.1177/0021998309347580

Spanoudaki, A., B. Albela, L. Bonneviot and M. Peyrard, 2005. The dynamics of water in nanoporous silica studied by dielectric spectroscopy. Eur. Phys. J. E. Soft Matter., 17: 2127. PMID: 15754084

Velmurugan, R. and T.P. Mohan, 2009. Epoxy-Clay Nanocomposites and hybrids: Synthesis and characterization. J. Reinf. Plastics Compo., 28: 1737. DOI: $10.1177 / 0731684407081439$

Zhang, H., X. Quan, S. Chen, H. Zhao, Y. Zhao and W. $\mathrm{Li}$, 2006. Zirconia and titania composite membranes for liquid phase separation: Preparation and characterization. Desalination, 190: 172-180. DOI: 10.1016/j.desal.2005.08.008

Zhao, F., H.R. Landis and S.J. Skerlos, 2005. Modeling of porous filter penneability via image-based stochastic reconstruction of spatial porosity correlations. Environ. Sci. Technol., 39: 239-247. PMID: 15667100 